\title{
Non-targeted Metabolite Profiling and Scavenging Activity Unveil the Nutraceutical Potential of Psyllium (Plantago ovata Forsk)
}

\author{
Manish K. Patel, Avinash Mishra* and Bhavanath Jha* \\ Division of Marine Biotechnology and Ecology, Central Salt and Marine Chemicals Research Institute, Bhavnagar, India
}

Non-targeted metabolomics implies that psyllium (Plantago ovata) is a rich source of natural antioxidants, PUFAs ( $\omega-3$ and $\omega-6$ fatty acids) and essential and sulfur-rich amino acids, as recommended by the FAO for human health. Psyllium contains phenolics and flavonoids that possess reducing capacity and reactive oxygen species (ROS)

OPEN ACCESS

Edited by:

Marta Wilton Vasconcelos, Universidade Católica Portuguesa,

Portugal

Reviewed by:

Ana-Flor Lopez-Millan,

Estacion Experimental de Aula

Dei-Consejo Superior de Investigaciones Cientificas, Spain Ana Gomes,

Universidade Católica Portuguesa,

Portugal

*Correspondence: Avinash Mishra avinash@csmcri.org; Bhavanath Jha

bjha@csmcri.org

Specialty section: This article was submitted to Plant Nutrition, a section of the journal

Frontiers in Plant Science

Received: 07 October 2015

Accepted: 21 March 2016

Published: 05 April 2016

Citation:

Patel MK, Mishra A and Jha B (2016)

Non-targeted Metabolite Profiling

and Scavenging Activity Unveil the Nutraceutical Potential of Psyllium

(Plantago ovata Forsk).

Front. Plant Sci. 7:431.

doi: 10.3389/fpls.2016.00431 scavenging activities. In leaves, seeds, and husks, about 76, 78, 58\% polyunsaturated, $21,15,20 \%$ saturated, and 3, 7, 22\% monounsaturated fatty acids were found, respectively. A range of FAs (C12 to $\mathrm{C} 24)$ was detected in psyllium and among different plant parts, a high content of the nutritive indicators $\omega$-3 alpha-linolenic acid $(57 \%)$ and $\omega-6$ linoleic acid (18\%) was detected in leaves. Similarly, total content of phenolics and the essential amino acid valine were also detected utmost in leaves followed by sulfur-rich amino acids and flavonoids. In total, 36 different metabolites were identified in psyllium, out of which 26 (13 each) metabolites were detected in leaves and seeds, whereas the remaining 10 were found in the husk. Most of the metabolites are natural antioxidants, phenolics, flavonoids, or alkaloids and can be used as nutrient supplements. Moreover, these metabolites have been reported to have several pharmaceutical applications, including anti-cancer activity. Natural plant ROS scavengers, saponins, were also detected. Based on metabolomic data, the probable presence of a flavonoid biosynthesis pathway was inferred, which provides useful insight for metabolic engineering in the future. Non-targeted metabolomics, antioxidants and scavenging activities reveal the nutraceutical potential of the plant and also suggest that psyllium leaves can be used as a green salad as a dietary supplement to daily food.

Keywords: antioxidant, bioactivity, isabgol, medicinal plant, metabolomics

\section{INTRODUCTION}

Psyllium (Plantago ovata Forsk) is an annual, herbaceous, medicinal plant belonging to the Plantaginaceae family and is widely cultivated in tropical regions of the world, such as India, Iran, Egypt, China, Korea, Japan, etc. (Chevallier, 1996). India is the largest producer of psyllium, which has been used since ancient times as a traditional herbal medicine in ayurvedic and allopathic preparations (Kirtikar and Basu, 1918). Its husk (commonly known as isabgol) and seed contain mucilaginous compounds of medicinal value and psylliums are used as a thickening agent in the pharmaceutical industry for manufacturing tablets. The husk is the white membranous structure 
covering the seed, which is a laxative and is particularly beneficial as a prophylactic in the treatment of bowel obstructions, constipation, diarrhea and dysentery (Chevallier, 1996).

Plantago ovata plant parts (leaves, seeds, and husks) are rich in bioactive compounds and different primary and secondary metabolites (Talukder et al., 2015). Among these, the most abundant compounds are fatty acids, amino acids, polyphenols, and flavonoids. One member of the Plantaginaceae contains an unusual hydroxy fatty acid, 9-hydroxy-cis-11-octadecenoic acid, which is an isomer of ricinoleic acid (Ahmad et al., 1980). Metabolites such as polyphenols and flavonoids are produced by secondary metabolism processes of Plantago, and possess a prominent antioxidant activity (Samuelsen, 2000; Beara et al., 2009). Polyphenols are considered to be very effective in the treatment of different types of neurodegenerative diseases, cardiovascular diseases and cancer, and are also involved in antioxidant activities, such as the scavenging of 2,2-azinobis(3-ethylbenzothiazoline-6-sulphonic acid; ABTS), 2,2-diphenyl1-picrylhydrazyl (DPPH) and hydroxyl radicals (Balasundram et al., 2006; Shahidi and Ambigaipalan, 2015). Many biological activities have been found associated with flavonoids and phenolic acids, such as anti-microbial, anti-hepatotoxic, antiosteoporotic, anti-ulcer, immunomodulatory, anti-proliferative, and apoptotic activities (Al-Fayez et al., 2006; Gould and Lister, 2006; Grotewold, 2006). Most plant species have a robust defense system against reactive oxygen species (ROS)-induced oxidative stress (Niki et al., 1994; Chaturvedi et al., 2014; Tiwari et al., 2015). ROS can play a key role in cell damage by lipid peroxidation of membrane lipids (Braca et al., 2002; Joshi et al., 2013; Patel et al., 2015). Lipid peroxidation is an oxidative alteration of fatty acids (in the cellular membrane) that produces several types of scavenging free radicals (Niki et al., 1994). When ROS attack proteins, they generate protein carbonyls and other modifications in amino-acid residues, resulting in the destruction of protein function (Khan et al., 2010). Studies on medicinal plants, herbal plants and vegetables have indicated the presence of free-radical scavenging and antioxidant compounds, such as flavonoids, phenolics, terpenoids, saponines, coumarins, cardiac glycosides, tannins, and proanthocyanidins (Saeed et al., 2012). Previously, many plant extracts have been examined for different ROS-scavenging activities, including $\mathrm{DPPH}$, superoxide, nitric oxide, reducing power and for phenolic and flavonoid content and total antioxidant activity (Mishra et al., 2015; Pandey et al., 2015). The use of medicinal plants with high constituents of antioxidant and free-radical scavenging compounds has been proposed as an effective therapeutic approach against hepatic and oxidative damage (Gould and Lister, 2006; Embuscado, 2015).

Plant metabolomics (metabolic profiling) has become an invaluable tool to study all the metabolites of plant tissues that have distinct chemical properties (Jorge et al., 2015). Plants possess the highest metabolic network complexity of all living organisms (Dersch et al., 2016). Metabolites are not only end products; they are also intermediates and substrates of metabolic processes and contribute toward plant adaptation. It is estimated that the plant kingdom alone is responsible for the synthesis of more than 200,000 metabolites, which are involved in various cellular processes (Pichersky and Gang, 2000; Fiehn, 2002). In the past decade, many analytical tools, such as gas chromatography mass spectrometry (GC-MS), high-performance liquid chromatography (HPLC), and liquid chromatography mass spectrometry (LC-MS) have been widely used within metabolomics for the identification and quantification of metabolites from different plant tissues. Metabolomics is the newest high-throughput technology for the qualitative and quantitative analysis of metabolites (Khakimov et al., 2014). Metabolite analysis helps to elucidate the function and pathways involved in the production of pharmacologically active compounds from plants (Rischer et al., 2006). Comprehensive metabolite analysis provides a useful insight into the existing metabolic pathways and also uncovers the network of metabolic pathways that are involved in different responses to specific stresses to be identified (Töpfer et al., 2015). Cross talk occurs between metabolites and environmental stress, which maintains the physio-biochemical status of the plant (Pandey et al., 2015). Furthermore, metabolite analysis is also emerging as a key tool in drug discovery processes (Fillet and Frédérich, 2015).

Psyllium is globally popular as a laxative, it is considered as a potential source of dietary supplementation and possesses important biological antioxidant and anti-inflammatory properties (Samuelsen, 2000; Beara et al., 2009). Studying the effect of organic additives in plant polyphenol accumulation is extremely important. No information is available to date concerning the metabolomics of this important plant. Therefore, this study was carried out to perform metabolic profiling and to characterize the antioxidant scavenging activities from different plant parts, e.g., leaves, seeds, and husks. Additionally, the total phenolic and flavonoid content was also estimated, a phytochemical analysis was performed, and a potential flavonoid biosynthesis pathway was inferred. This study provides useful insight into the metabolic responses of different plant parts of $P$. ovata, which reveal the potential for the plant to be used as a dietary supplement and in the nutraceutical industry.

\section{MATERIALS AND METHODS}

\section{Plant Material}

Seeds of $P$. ovata were procured from Seed Spices Research Station, Jagudan, Mehsana, Gujarat, India and were germinated in a plot (Figure 1) containing garden soil, under natural agroclimatic field conditions from November, 2014 to March, 2015 (Jat et al., 2015). A plot consisted of eight rows and each row contained about eight plants. The plants were irrigated every alternate day with tap water. Leaves from 3-months-old plants, mature seeds and husk were harvested and immediately used for further study.

\section{Lipid Extraction and Fatty Acid Profiling}

Total lipid was extracted from $1 \mathrm{~g}$ biomass of leaves, seeds, and husk using the solvent chloroform-methanol (v/v, 1:2) extraction method followed by washing with an equal volume of phosphate 


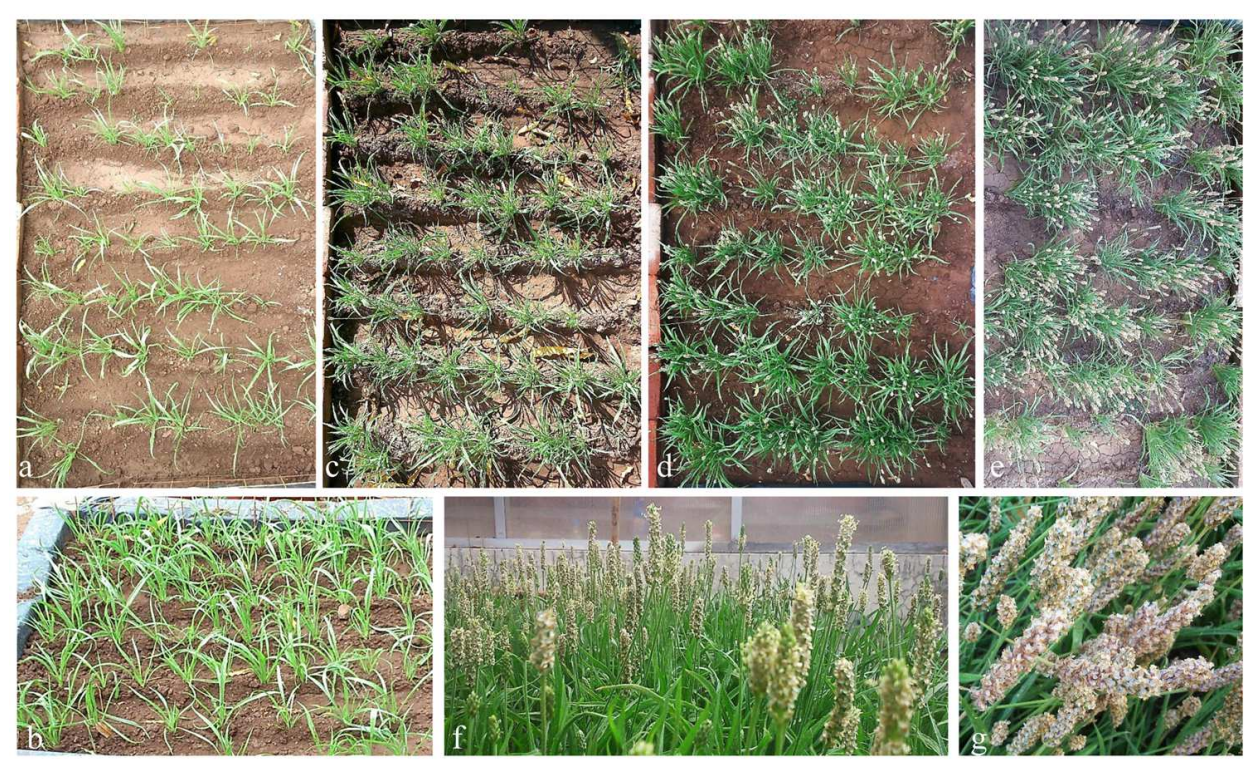

FIGURE 1 | Psyllium plants grown in plots under natural agro-climatic condition. Plants were grown under natural agro-climatic conditions in a field. Plant growth status at 15 days (a), 40 days (b), 60 days (c), 90 days (d), 100 days (e), and 120 days (f) of growth. Plants showing seed maturity at 120 days (g) of growth.

buffer ( $\mathrm{pH} 7.5$ ), and stored at $-20^{\circ} \mathrm{C}$ for further analysis (Bligh and Dyer, 1959). The corresponding fatty acid methyl esters (FAMEs) were prepared by transmethylation (Kumari et al., 2013). Lipid samples were transmethylated by adding $\mathrm{NaOH}(\mathrm{v} / \mathrm{v}$, $1 \%$ in methanol; $1 \mathrm{ml}$ ) in the vessels, followed by heating at $55^{\circ} \mathrm{C}$ for $15 \mathrm{~min}$. Thereafter, $2 \mathrm{ml}$ methanolic $\mathrm{HCl}(\mathrm{v} / \mathrm{v}, 5 \%)$ was added and the vessels were further heated at $55^{\circ} \mathrm{C}$ for $15 \mathrm{~min}$. Derivative FAMEs were extracted in aqueous hexane (v/v, 1:2; $3 \mathrm{ml})$, dried under $\mathrm{N}_{2}$ and dissolved in hexane $(200 \mu \mathrm{l})$.

Samples of FAME of each plant part were analyzed by a GC coupled with a mass spectrometer (GCMS-QP2010, Shimadzu, Japan) equipped with an auto-sampler (AOC-5000) using a RTX 5MS capillary column (60 m length, $0.25 \mathrm{~mm}$ diameter, and $0.50 \mu \mathrm{m}$ thickness; Rastek, USA). Helium (99.9\% purity) gas was used as a carrier gas with a flow rate of $1 \mathrm{ml} \mathrm{min} \mathrm{m}^{-1}$ and a pre-column pressure of $49.7 \mathrm{kPa}$. The initial column temperature was $40^{\circ} \mathrm{C}$ for $3.0 \mathrm{~min}$, followed by $5^{\circ} \mathrm{C} \mathrm{min}-1$ increments up to $230^{\circ} \mathrm{C}$ and finally, $230^{\circ} \mathrm{C}$ held for $40 \mathrm{~min}$. The injection volume, temperature, and total analysis time were $1 \mu \mathrm{l}, 240^{\circ} \mathrm{C}$ and $67 \mathrm{~min}$, respectively. The mass spectrometer operated in ionization mode, with electron impact at $70 \mathrm{eV}$ and the temperature of the ion sources and quadrupole was $200^{\circ} \mathrm{C}$ (Mishra et al., 2015). The limit of detection (LOD) and limit of quantitation (LOQ) of the instrument were established (Supplementary Table S1) and FAME peaks were acquired over the $40-400 \mathrm{~m} / \mathrm{z}$ range. The MS peaks of samples were compared with the retention times of standards (FAME Mix C4-C24, Supelco, USA and 7-hexedecenoic acid methyl ester, Cayman Chemicals, USA) by GCMS analysis and were quantified by area normalization.

The total content of saturated fatty acids (SFAs) and unsaturated fatty acids [monounsaturated fatty acids (MUFA) and polyunsaturated fatty acids (PUFA)] were determined by summation of the percentage quantity of the corresponding fatty acids. Unsaturation index (UI; Poerschmann et al., 2004) and degree of unsaturation (DU; Yu et al., 2012) were calculated using the following equation

$$
\begin{aligned}
\text { Degree of unsaturation }(\mathrm{DU})= & (\text { MUFA, w\% })+ \\
& 2(\text { PUFA, w\% }) \\
\text { Unsaturation index }(\mathrm{UI})= & \Sigma(\mathrm{UFA}, \mathrm{w} \% \times \text { number of } \\
& \text { double bonds }) .
\end{aligned}
$$

\section{Amino Acid Profiling}

Plant samples (5 mg each dried and powdered; leaves, seed and husk) were hydrolysed in a glass vessel with $\mathrm{HCl}(6 \mathrm{~N}, 500 \mu \mathrm{l})$. Glass vessels were made air-free by flushing with $\mathrm{N}_{2}$ and were sealed. The samples were hydrolysed at $110^{\circ} \mathrm{C}$ for $24 \mathrm{~h}$ in a hot-air oven. After hydrolysis, the vessels were broken and the samples were vacuum-dried in a desiccator. The mixture of ethanolwater-TEA (v/v, 2:2:1; $500 \mu \mathrm{l})$ was added to the vessels, which contained hydrolysed samples and an amino acid standard $(10 \mu \mathrm{l}$, AAS18, Sigma, USA) for neutralization. The samples were mixed properly by vortexing and were then vacuum-dried. Thereafter, samples were derivatised by adding a mixture of ethanol-waterTEA-PITC (v/v, 7:1:1:1; $500 \mu \mathrm{l})$ and were vortexed for proper mixing. The reaction mixture was kept at room temperature for $20 \mathrm{~min}$, was vacuum-dried and finally dissolved in $400 \mu \mathrm{l}$ $\mathrm{Na}_{2} \mathrm{HPO}_{4}$ buffer $(5 \mathrm{mM}, \mathrm{pH} 7.4)$ containing acetonitrile (v/v, $5 \%)$. Samples were filtered with a $0.2 \mu \mathrm{m}$ membrane and the amino acid composition was analyzed using HPLC (Kwanyuen and Burton, 2010). 
The standard (AAS18, Sigma, USA) and samples were injected and analyzed with a HPLC system (Waters Alliance model, 2996-seperation module with an auto-sampler, USA) equipped with a Luna-C18 reversed-phase $(5.0 \mu \mathrm{m}, 4.6 \mathrm{~mm} \times 150 \mathrm{~mm}$, Phenomenex, USA) column (Mishra and Jha, 2009; Kwanyuen and Burton, 2010). The amino acids were separated and eluted by a gradient resulting from mixing eluents $\mathrm{A}$ and $\mathrm{B}$. Eluent A consisted of $150 \mathrm{mM} \mathrm{CH}_{3} \mathrm{COONa}_{3} \mathrm{H}_{2} \mathrm{O}, 0.05 \%(\mathrm{v} / \mathrm{v})$ TEA and $6 \%(\mathrm{v} / \mathrm{v})$ acetonitrile, $\mathrm{pH} 6.4$, whereas eluent $\mathrm{B}$ consisted of acetonitrile:water (v/v, 6:4). Both eluents were properly mixed and filtered through a $0.2 \mu \mathrm{m}$ membrane. The flow rate was $1 \mathrm{ml} \mathrm{min}{ }^{-1}$ throughout and the gradient consisted of the following profiles: $100 \% \mathrm{~A}$ at the start, $80 \% \mathrm{~A}$ and $20 \% \mathrm{~B}$ at $5.5 \mathrm{~min}, 54 \% \mathrm{~A}$ and $46 \% \mathrm{~B}$ at $10 \mathrm{~min}, 100 \% \mathrm{~B}$ at $10.5-$ $12.5 \mathrm{~min}, 100 \% \mathrm{~A}$ at $13 \mathrm{~min}$. The PITC-derivatised amino acids were eluted from the column and recorded at $254 \mathrm{~nm}$. The relative proportion of the peak area was calculated to estimate the amino acid composition per gram dry weight of plant samples.

\section{Screening of Phytochemicals}

A phytochemical analysis of psyllium plant parts (leaves, seeds, and husk) was performed to determine the presence of alkaloids, terpenoids, saponins, coumarins, flavonoids, cardiac glycosides, and tannins. To test for the presence of alkaloids in the plant parts, $0.1 \mathrm{~g}$ sample was mixed with $4 \mathrm{ml} 1 \% \mathrm{HCl}$ in a glass tube, heated in a water bath, and filtered. A $2 \mathrm{ml}$ aliquot of filtrate was treated with Dragendroff's reagent (potassium bismuth) and the appearance of turbidity or precipitation demonstrated the presence of alkaloids (Harborne, 1973).

The presence of terpenoids in the plant parts was confirmed by the appearance of a reddish brown interface following mixing $1 \mathrm{mg} \mathrm{ml}^{-1}$ aqueous extract with $2 \mathrm{ml}$ chloroform, followed by the addition of $3 \mathrm{ml}$ concentrated $\mathrm{H}_{2} \mathrm{SO}_{4}$ (Harborne, 1973). Saponins were tested by mixing about $20 \mathrm{mg}$ sample with distilled water $(15 \mathrm{ml})$, incubating in a boiling water bath for $5 \mathrm{~min}$ and filtering. The filtrate was diluted with $5 \mathrm{ml}$ water and was vortexed vigorously to form froth. The ability of saponins to produce an emulsion with oil was tested by mixing three drops of olive oil with the froth (Harborne, 1973).

To test for the presence of coumarins, about $30 \mathrm{mg}$ sample was dropped onto filter paper moistened with $1 \mathrm{~N} \mathrm{NaOH}$. The filter paper was placed in a test tube and was incubated in a boiling water bath for a few minutes. The filter paper was examined under UV light and a yellow florescence indicated the presence of coumarins (Trease and Evans, 1989). The presence of flavonoids was demonstrated by the appearance of a yellow color (Sofowora, 1993), when $3 \mathrm{mg}$ filtered aqueous sample (5 $\mathrm{ml}$ water) was mixed with $2 \mathrm{ml}$ dilute ammonia solution followed by a few drops of concentrated $\mathrm{H}_{2} \mathrm{SO}_{4}$.

To test for the presence of cardiac glycosides, $10 \mathrm{mg}$ plant sample dissolved in methanol was mixed with $2 \mathrm{ml}$ of glacial acetic acid and one drop of $\mathrm{FeCl}_{3}$ solution was added. If cardiac glycosides were present, a brown ring appeared at interface after adding $1 \mathrm{ml}$ of concentrated $\mathrm{H}_{2} \mathrm{SO}_{4}$ to the above mixture (Trease and Evans, 1989). To test for tannins $10 \mathrm{mg}$ filtered aqueous plant sample (in $5 \mathrm{ml}$ boiled water) was mixed with few drops of $0.1 \%$ $\mathrm{FeCl}_{3}$ and the appearance of a brownish green or blue-black color confirmed the existence of tannins(Sofowora, 1993).

\section{Extract Preparation}

Plant sample (leaves, seeds, and husk; $10 \mathrm{~g}$ ) were ground in liquid $\mathrm{N}_{2}$, transferred to aqueous methanol (v/v, 70\%) and kept overnight for extraction. The mixture was centrifuged at $8000 \mathrm{rpm}$ for $10 \mathrm{~min}$ and the supernatant was collected. The extraction (in aqueous methanol) was repeated twice. Collected supernatants were concentrated in a rotary evaporator (150-100 mbar at $37^{\circ} \mathrm{C}$ ) and were lyophilised. The dried residue was stored at $-20^{\circ} \mathrm{C}$ until use.

To determine different activities (antioxidant and scavenging) and contents (phenolic and flavonoid), dried residue was solubilised in distilled water, and absorbance readings of samples (plant extracts) were compared with a standard curve, which was created by the same method, using known amounts of the corresponding standard. All tests were performed in triplicate and values were expressed as mean $\pm \mathrm{SE}$.

\section{Total Phenolic Content}

Total phenolic content of the plant extracts was determined by the Folin-Ciocalteu (FC) reagents using gallic acid as a standard (Hazra et al., 2008; Mishra et al., 2015). Different concentrations of the plant extracts $\left(50-1000 \mu \mathrm{g} \mathrm{ml} \mathrm{m}^{-1}\right)$ were mixed with $2.5 \mathrm{ml} 0.2 \mathrm{~N}$ Folin-Ciocalteu reagent (Sigma-Aldrich, USA) and were incubated for $5 \mathrm{~min}$, followed by the addition of $2 \mathrm{ml}$ sodium carbonate $\left(\mathrm{Na}_{2} \mathrm{CO}_{3} ; 75 \mathrm{~g} \mathrm{l}^{-1}\right)$. The reaction mixtures were incubated for a further $90 \mathrm{~min}$ at room temperature. The absorbance was measured at $760 \mathrm{~nm}$ and the total phenolic content was calculated as $\mathrm{mg} \mathrm{ml}^{-1}$ gallic acid per $100 \mathrm{mg}$ extract from a standard curve.

\section{Total Flavonoid Content}

To determine the total flavonoid content, different concentrations of plant extracts (50-1000 $\mu \mathrm{g} \mathrm{ml}^{-1}$ ) were added to $0.3 \mathrm{ml} \mathrm{NaNO}$ (v/v, 5\%) and were incubated for $5 \mathrm{~min}$ at room temperature. Thereafter, $0.3 \mathrm{ml} \mathrm{AlCl}_{3}(\mathrm{v} / \mathrm{v}, 10 \%)$ and $2 \mathrm{ml} \mathrm{NaOH}(1 \mathrm{M})$ were added. The reaction mixture was diluted with water and absorbance was measured at $510 \mathrm{~nm}$ and the total flavonoid content was calculated as $\mathrm{mg} \mathrm{ml}^{-1}$ quercetin per $100 \mathrm{mg}$ extract from a standard curve (Zhishen et al., 1999; Mishra et al., 2015).

\section{ABTS Scavenging Activity}

Total antioxidant activity was measured by comparing the $\mathrm{ABTS}^{+}$radical cation scavenging ability of plant extracts with that of the standard, trolox (Re et al., 1999; Hazra et al., 2008). The ABTS diammonium salt $(7 \mathrm{mM})$ solution was mixed with potassium persulfate $(2.45 \mathrm{mM})$ and the mixtures were incubated in the dark for $12-16 \mathrm{~h}$ at room temperature to generate $\mathrm{ABTS}^{+}$radical cations. The ABTS radical cation solution was diluted with water for an initial absorbance of the solution of about $0.70 \pm 0.02$ at $735 \mathrm{~nm}$. The radical cation scavenging activity was assessed using $1 \mathrm{ml}$ of the diluted radical cation 
solution mixed with different concentrations of the plant extracts (50-300 $\mu \mathrm{g} \mathrm{ml}^{-1}$ ) or the standard (1-5 $\mu \mathrm{g} \mathrm{ml}^{-1}$ trolox). After incubation, the absorbance was measured at $734 \mathrm{~nm}$. The percentage inhibition of absorbance was calculated and the activity of different extracts (leaves, seeds, and husk) was compared.

\section{DPPH Assay}

Scavenging of the DPPH free radical was determined using trolox as a standard (Saeed et al., 2012). The DPPH stock solution (w/v, $0.024 \%$ in methanol) was diluted to make a working solution by adding methanol until an absorbance of $0.98 \pm 0.02$ at $517 \mathrm{~nm}$ was obtained. Different concentrations of plant extracts (50$300 \mu \mathrm{g} \mathrm{ml}^{-1}$ ) were mixed with $3 \mathrm{ml}$ working stock solution and were incubated overnight at room temperature in the dark. The absorbance was measured at $517 \mathrm{~nm}$ and the radical scavenging activities of the plant extracts were estimated using the following equation:

$$
\begin{aligned}
& \mathrm{OD}_{517} \text { of Control - } \\
& \text { Scavenging activity }(\%)=\left[\frac{\mathrm{OD}_{517} \text { of Extract }}{\mathrm{OD}_{517} \text { of Control }}\right] \times 100 \text {. }
\end{aligned}
$$

\section{Reducing Power Assay}

Different concentrations of the plant extracts $\left(5-80 \mu \mathrm{g} \mathrm{ml}^{-1}\right)$ or ascorbic acid (as a positive standard) were mixed with $1 \mathrm{ml}$ phosphate buffer $(0.2 \mathrm{M}, \mathrm{pH} 6.6)$, then $1 \mathrm{ml}$ of $\mathrm{K}_{3} \mathrm{Fe}(\mathrm{CN})_{6}$ $\left(10 \mathrm{mg} \mathrm{ml}^{-1}\right.$ ) was added and the mixture was incubated at $50^{\circ} \mathrm{C}$ for $20 \mathrm{~min}$ in a water bath. After incubation, $1 \mathrm{ml}$ trichloroacetic acid $\left(100 \mathrm{mg} \mathrm{l}^{-1}\right)$ was added to terminate the reaction. The reaction mixture was centrifuged at $8000 \mathrm{rpm}$ for $10 \mathrm{~min}$ at room temperature and the supernatant was collected in a 5-ml tube. A 1-ml aliquot of the diluted supernatant was mixed with $0.2 \mathrm{ml}$ freshly prepared $\mathrm{FeCl}_{3}$ (w/v, 0.1\%) and was incubated for $10 \mathrm{~min}$ at room temperature. The absorbance was measured at $700 \mathrm{~nm}$, the scavenging activity was measured and the reducing power was compared.

$$
\text { Scavenging activity }(\%)=\left[\frac{\mathrm{OD}_{700} \text { of Control }-}{\mathrm{OD}_{700} \text { of Extract }}\right] \times 100
$$

\section{Superoxide Assay}

The activity of superoxide anion was measured by the reduction of nitro blue tetrazolium (NBT) according to a previously described method (Hazra et al., 2008). Superoxide anion radicals are generated by a non-enzymatic phenazine methosulphate/nicotinamide adenine dinucleotide (PMS/NADH) system. These superoxide radicals reduce NBT to a purple-colored formazan. The reaction mixture contained NBT $(50 \mu \mathrm{M})$, PMS $(15 \mu \mathrm{M})$, NADH $(73 \mu \mathrm{M})$ in phosphate buffer $(20 \mathrm{mM}, \mathrm{pH} 7.4)$ and various concentrations of the plant extracts (50-300 $\mathrm{g} \mathrm{ml}^{-1}$ ). The mixture was incubated for $5 \mathrm{~min}$ at room temperature and absorbance was measured at $562 \mathrm{~nm}$. Quercetin was used as standard. The inhibition of superoxide anion radical generation was estimated using the following equation:

$$
\text { Scavenging activity }(\%)=\left[\frac{\mathrm{OD}_{562} \text { of Control }-}{\mathrm{OD}_{562} \text { of Extract }}\right] \times 100
$$

\section{Metabolites Profiling}

Plant samples (leaves, seed, and husk; $100 \mathrm{mg}$ ) were ground and the total plant metabolites were extracted using a modified method (Mishra et al., 2015) by adding ice-cold aqueous methanol (v/v, 70\%) followed by vortexing. The sample was placed in an ultrasonic water bath (MRC, Israel) at a frequency of $40 \mathrm{kHz}$ for $1 \mathrm{~h}$. The supernatant was collected after centrifugation $\left(20000 \mathrm{rpm}\right.$ at $25^{\circ} \mathrm{C}$ for $\left.10 \mathrm{~min}\right)$ and was filtered $(0.2 \mu \mathrm{m}$ membrane).

Metabolites were analyzed by LC coupled with TOF MS/MS (Micromass, Waters, USA) and were identified by comparing LCTOF MS/MS peaks using the on-line METLIN database (Zhu et al., 2013). The LC MS/MS parameters were a source and desolvation temperature of 110 and $200^{\circ} \mathrm{C}$ respectively; $2.5 \mathrm{kV}$ was applied to the electrospray capillary, the cone voltage was $25 \mathrm{~V}$ and nitrogen was used as the collision gas. Samples were directly injected to the ESI-MS at a $50 \mu \mathrm{l} \mathrm{min}^{-1}$ flow rate using a syringe pump, and the extracted metabolites were examined in negative-ion ESI/MS-MS mode. The scanning range was 0$1000 \mathrm{~m} / \mathrm{z}$, with an acquisition rate of $0.25 \mathrm{~s}$ and an inter-scan delay of 0.1 s. For peak integration, the background of each spectrum was subtracted, the data were smoothed and cantered and the peaks were integrated using the Mass Lynx software version 4.1 (Micromass, Waters).

\section{Pathway Analysis}

A potential flavonoid biosynthesis pathway was predicted by in silico comparative and interactive pathway topology analysis using the metabolomic data (Xia et al., 2015). A total of 24 metabolites was used for the analysis and compounds with no match were excluded from the subsequent pathway analysis (Supplementary Table S2). The metabolome data were uploaded and subsequently compared with the KEGG pathway library of Oryza sativa japonica and Arabidopsis thaliana by overrepresentation analysis using Fishers' exact test. The pathway topology was analyzed by a well-established node of centrality measures to estimate the node and a graph-based method was used to analyze the biological networks (Aittokallio and Schwikowski, 2006). The degree of centrality used for the comparison among different pathways was calculated. The node importance value was calculated from centrality measures and was further normalized by the sum of the importance of the pathway. The pathway was predicted among different pathways using the statistical $p$-values from enrichment analysis, which was further adjusted for multiple testing. The pathway was selected to show maximum hits, which is actually a matched number from the uploaded data. The significance of the analysis was calculated as a $p$-value from the enrichment analysis, as the Holm $p$-value, in which the $p$-value was adjusted by the Holm-Bonferroni method, 
as the FDR $p$-value by adjusting the $p$-value using the false discovery rate and finally, the impact value was calculated using pathway topology analysis (Xia et al., 2015).

\section{Statistical Analysis}

All experiments were carried out three times and for each experiment, three biological replicates were performed (i.e., three plant samples per experiment). All data were subjected to analysis of variance (ANOVA); $p<0.05$ was considered as the threshold for statistical significance and values were expressed as the mean \pm SE (standard error of the mean). All lipid and fatty acid datasets were analyzed individually and in combination by principal component analysis (PCA) and respective heat maps were generated.

\section{RESULTS}

\section{Fatty Acid Composition}

The total fatty acid content was $26.17 \pm 1.35,156.89 \pm 4.39$, and $28.50 \pm 2.21 \mathrm{mg}$ per gram FW of leaves, seeds, and husk, respectively (Supplementary Table S3). The total fatty acid (FA) content of leaves, seeds, and husk consisted of about 76, 78, 58\% polyunsaturated, 21, 15, 20\% saturated, and 3, 7, 22\% MUFA, respectively (Table 1 ). The maximum degree of unsaturation (DU) was observed in seeds followed by in leaves and the husk, whereas the maximum UI was observed in leaves followed by in seeds and the husk. Among PUFAs, C18 PUFA dominated in all plant parts, and notably, C22 PUFAs and C20 PUFAs were not detected in leaves and seeds, respectively.

TABLE 1 | Fatty acid profile of different psyllium plant parts.

\begin{tabular}{|c|c|c|c|c|}
\hline Fatty acids & Name of fatty acids & Leaves & Seeds & Husk \\
\hline$\Sigma$ SFA & & $21.012 \pm 0.2$ & $14.46 \pm 0.65$ & $19.88 \pm 0.46$ \\
\hline$\Sigma$ PUFA & & $76.12 \pm 0.52$ & $78.2 \pm 0.31$ & $58.55 \pm 0.39$ \\
\hline$\Sigma 18$ PUFA & & $75.06 \pm 0.21$ & $75.82 \pm 1.39$ & $48.25 \pm 1.48$ \\
\hline$\Sigma 20$ PUFA & & $1.06 \pm 0.12$ & nd & $4.67 \pm 0.12$ \\
\hline Ul & & $212.17 \pm 3.44$ & $185.5 \pm 4.45$ & $164.31 \pm 7.79$ \\
\hline DU & & $155.09 \pm .39$ & $163.74 \pm 0.73$ & $138.67 \pm 0.84$ \\
\hline n6/n3 & & $0.31 \pm 0.57$ & $4.49 \pm 0.57$ & $6.36 \pm 1.12$ \\
\hline n9/n3 & & $0.03 \pm 0.29$ & $0.5 \pm 0.2$ & $2.98 \pm 0.48$ \\
\hline n9/n6 & & $0.1 \pm 0.01$ & $0.11 \pm 0.02$ & $0.47 \pm 0.01$ \\
\hline \multicolumn{5}{|c|}{ Fatty acids composition } \\
\hline C15:0 & Pentadecanoic acid & $0.12 \pm 0.01$ & $0.13 \pm 0.01$ & $0.1 \pm 0.01$ \\
\hline C15:1 (n-5) & Cis-10-pentadecenoic acid & nd & $0.05 \pm 0.004$ & nd \\
\hline C16:0 & Palmitic acid & $13.7 \pm 0.25$ & $6.56 \pm 0.63$ & $12.22 \pm 0.4$ \\
\hline $\mathrm{C} 16: 1(\mathrm{n}-7)$ & Palmitoleic acid & $0.12 \pm 0.01$ & $0.17 \pm 0.02$ & $0.1 \pm 0.02$ \\
\hline C17:0 & Heptadecanoic acid & $0.16 \pm 0.01$ & $0.22 \pm 0.01$ & $0.12 \pm 0.01$ \\
\hline$C 17: 1(n-7)$ & Cis-10-heptadecanoic acid & nd & $0.13 \pm 0.01$ & $0.07 \pm 0.01$ \\
\hline C18:0 & Stearic acid & $5.27 \pm 0.08$ & $5.8 \pm 0.06$ & $4.83 \pm 0.06$ \\
\hline C18:1 (n-9) & Oleic acid & $1.84 \pm 0.36$ & nd & $18.92 \pm 0.36$ \\
\hline C18:2 (n-6) & Linoleic acid & $18.14 \pm 0.57$ & $63.58 \pm 0.88$ & $45.1 \pm 1.31$ \\
\hline C18:3 (n-3) & Alpha-linolenic acid [ALA] & $56.92 \pm 0.62$ & $11.89 \pm 0.89$ & $2.73 \pm 0.28$ \\
\hline C18:3 (n-6) & Gamma-linolenic acid & nd & $0.36 \pm 0.01$ & $0.41 \pm 0.01$ \\
\hline C23:0 & Tricosanoic acid & nd & $0.08 \pm 0.01$ & nd \\
\hline $\mathrm{C} 24: 0$ & Lignoceric acid & $0.87 \pm 0.01$ & $0.16 \pm 0.01$ & nd \\
\hline
\end{tabular}

SFAs, Saturated fatty acids; MUFA, mono unsaturated fatty acids; PUFA, poly unsaturated fatty acids; UI, unsaturation index; DU, degree of unsaturation; nd, not detected. 
A range of FAs (C14 to $\mathrm{C} 24$ ) was detected, with a predominance of alpha-linolenic acid (C18:3, n-3; 57\%), linoleic acid (C18:2, n-6; 18\%), palmitic acid (C16:0; 14\%), and stearic acid (C18:0; 5\%) in leaves. A dominance of linoleic acid (C18:2, $\mathrm{n}-6 ; 64 \%)$ was detected in seeds, together with alpha-linolenic acid (C18:3, n-3; 12\%), cis-11-eicosenoic acid (C20:1, n-9; 7\%), palmitic acid $(\mathrm{C} 16: 0 ; 6.5 \%)$ and stearic acid $(\mathrm{C} 18: 0 ; 6 \%)$ as major FAs. In the husk, there was a dominance of linoleic acid (C18:2, n-6; 45\%) followed by oleic acid (C18:1, n-9; 19\%), palmitic acid (C16:0; 12\%), stearic acid (C18:0; 5\%), and cis11,14-eicosadienoic acid (C20:2; 5\%). Myristoleic acid (C14:1; $0.9 \%$ ) and cis-11,14,17-eicosadienoic acid (C20:3, n-3; 1\%) were detected in only in leaves. Similarly, cis-10-pentadecenoic acid $(\mathrm{C} 15: 1, \mathrm{n}-5 ; 0.5 \%)$ and tricosanoic acid (C23:0; 0.1\%) were present only in seed, whereas three FAs; cis-11,14-eicosadienoic acid (C20:2; 5\%), lauric acid (C12:0; 1\%), and erucic acid (C22:1, n-9; 0.4\%) were detected exclusively in the husk. Four FAs were not detected in leaves; myristic acid (C14:0), cis-10heptadecanoic acid (C17:1, n-7), gamma-linolenic acid (C18:3, n-6), and heneicosanoic acid (C21:0); however, these were present in seeds and in the husk as minor FAs. One FA, oleic acid (C18:1, n-9), which was present in the husk as a major FA was not detected in seeds; similarly, lignoceric acid (C24:0,) was present in leaves and seeds, but was not detected in the husk. PCA indicated that the total lipid and fatty acid composition was significantly dependent on the plant parts (Figure 2) and the heat map showed the differential fatty acid composition (Figure 3).

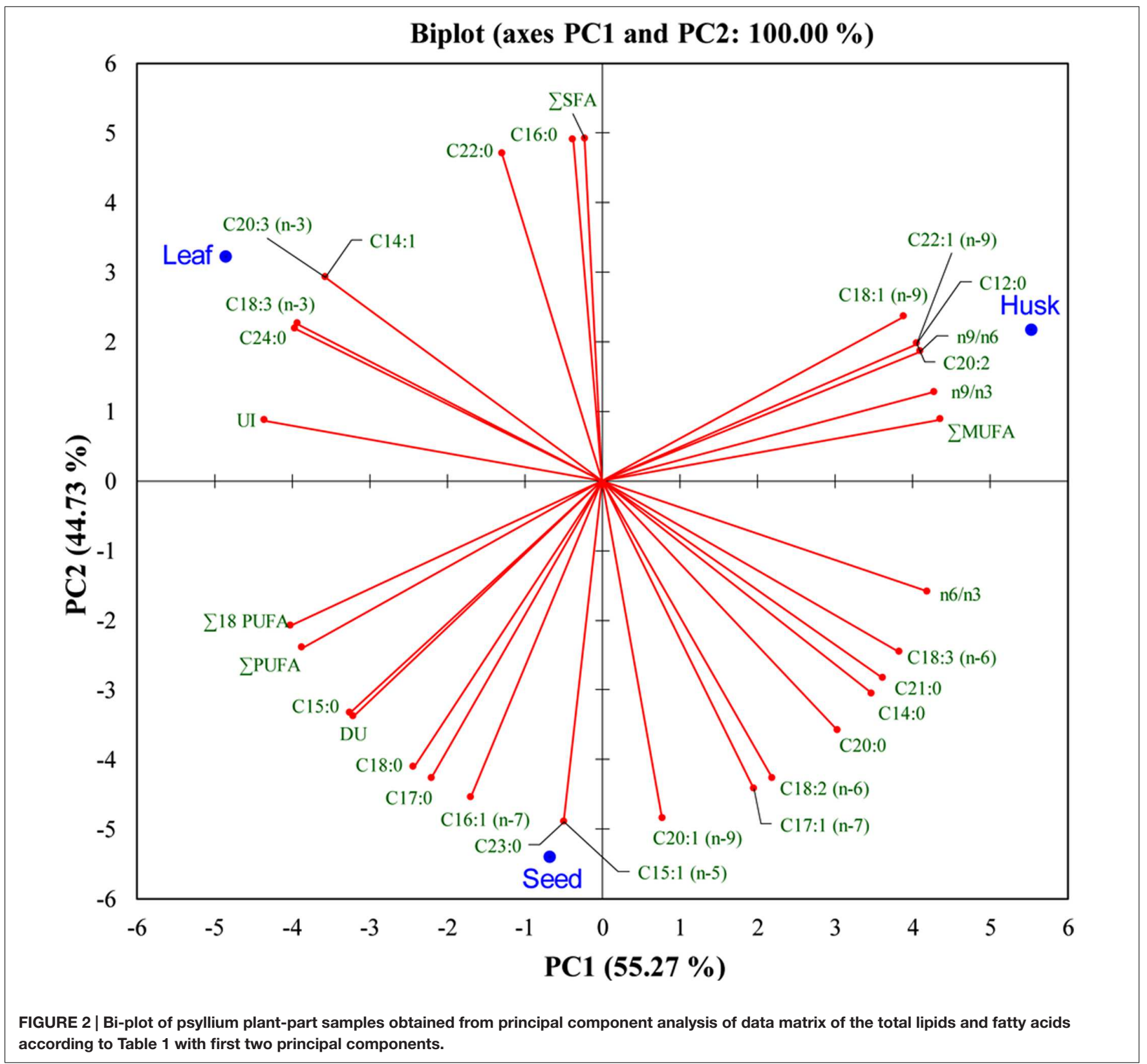




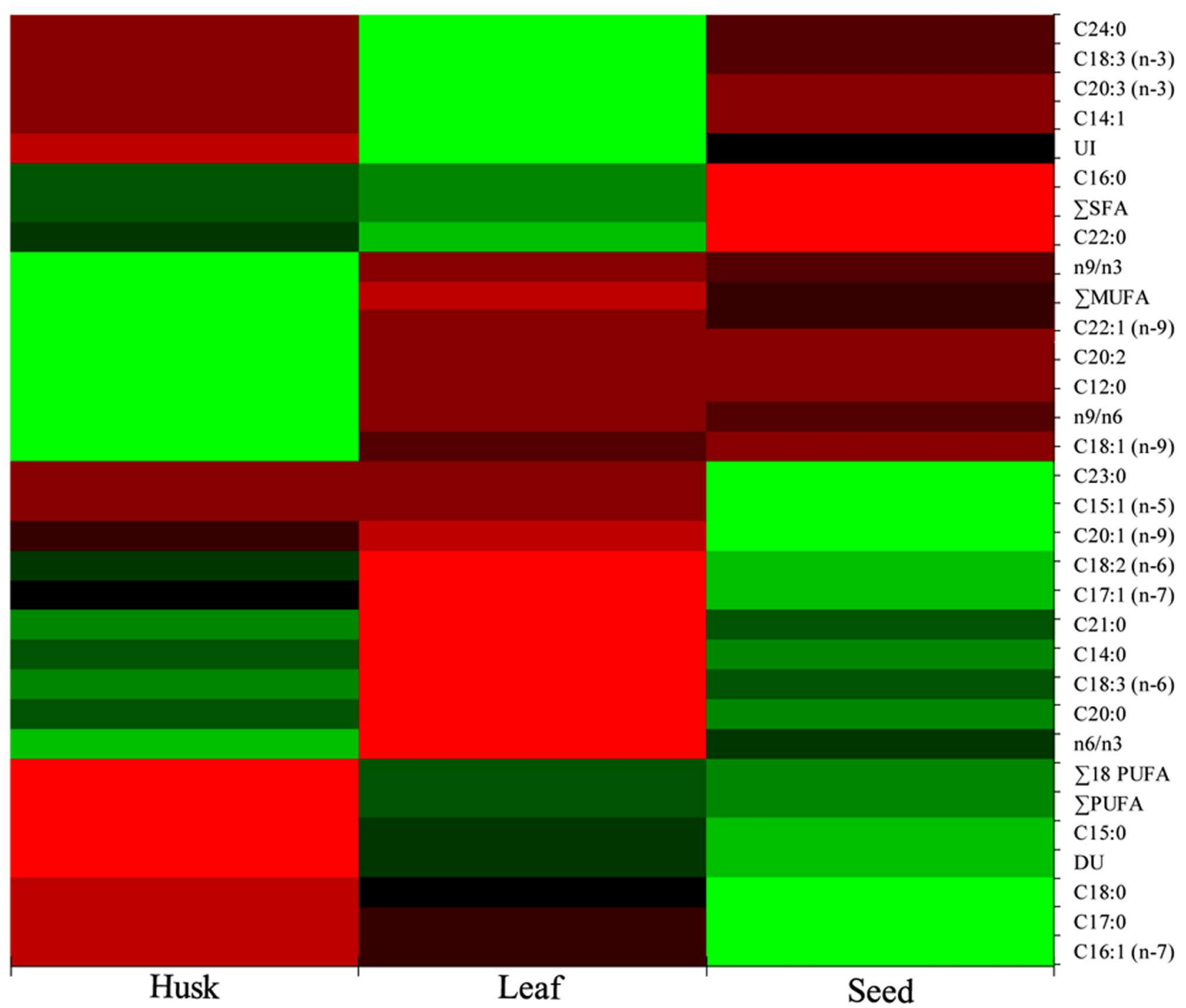

FIGURE 3 | Heat map of the total lipids and fatty acids composition showing spatial occurrence of lipids and fatty acids.

\section{Amino Acid Constituents}

In total, 17 amino acids were detected in leaves and seeds, whereas 14 amino acids were observed in the husk and were categorized as non-essential, essential, sulfur-rich and aromatic amino acids (Figure 4). Essential amino acids, isoleucine (1.17\%), threonine $(0.95 \%)$, leucine $(0.93 \%)$, histidine $(0.28 \%)$, and lysine $(0.27 \%)$ were significantly higher in leaves compared to seeds and husks, in which contents of these essential amino acids were insignificant (0.1-0.01\% of biomass). The highest levels of the essential amino acid valine was detected in leaves and seeds (about 3.0 and $1.0 \mathrm{~g}$ per $100 \mathrm{~g}$ biomass, respectively) followed by sulfur-rich amino acids. In contrast, aromatic amino acids were abundant in the husk compared to essential and nonessential amino acids. High amounts of almost all amino acids were detected in leaves and seeds compared to in the husk. The essential amino acids leucine and the sulfur-rich amino acids cysteine and methionine were not detected in the husk.

\section{Phytochemicals Assay, Total Phenolic and Flavonoid Contents}

Different edible plant parts (leaves, seeds, and husk) were screened to ascertain the occurrence of phytochemicals (Table 2). Alkaloids, flavonoids, cardiac glycosides, and tannins were detected in all plant parts. In contrast, terpenoids and saponines were absent in leaves, whereas coumarins were not detected in seeds and the husk. The total flavonoids was detected utmost in the leaves, followed by in seeds and the husk (Figure 5). Similarly, a high total phenolic content was observed in seeds followed by leaves and the husk.

\section{Scavenging and Reducing Activities}

The reducing capacity and scavenging activity of the plant extracts increased concomitantly with the extract concentration. The total antioxidant activity (expressed as the \% inhibition of 


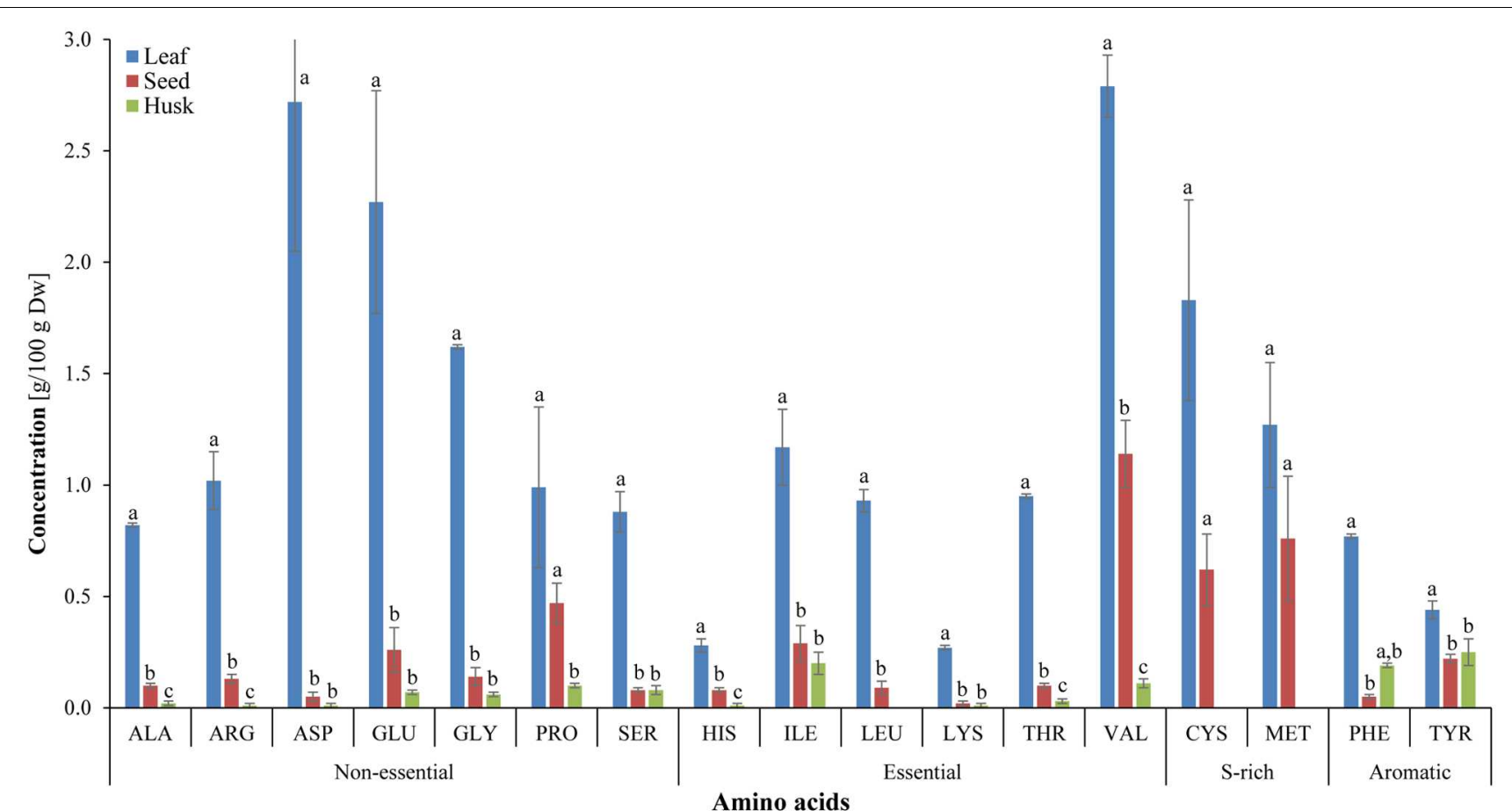

Amino acids

FIGURE 4 | Amino-acid composition of different psyllium plant parts. Value represents the mean \pm SE. Value represents the mean \pm SE and values of each amino acids with different letters are significant different at $p<0.05$.

TABLE 2 | Phytochemicals assay of psyllium plant extract.

\begin{tabular}{|c|c|c|c|c|c|c|c|}
\hline & Alkaloids & Terpenoids & Saponines & Coumarins & Flavonoids & Cardiac glycosides & Tannins \\
\hline Husk & + & + & + & - & + & + & + \\
\hline Leaf & + & - & - & + & + & + & + \\
\hline Seed & + & + & + & - & + & + & + \\
\hline
\end{tabular}

decolorisation of $\mathrm{ABTS}^{+}$) was found to be the highest in the seed extract followed by in leaf and husk extracts (Figure 6A). About $150 \mu \mathrm{g}$ seed extract showed $94 \%$ inhibition, whereas the same amount of inhibition was observed with $200 \mu \mathrm{g}$ leaf extract. In contrast, lower total antioxidant activity was observed with husk extract and about $300 \mu$ g extract was required for $90 \%$ inhibition. Similarly, the maximum DPPH scavenging activity was found for seed extract, followed by leaf and husk extracts (Figure 6B). About $85 \%$ scavenging activity was observed with 250 and $300 \mu \mathrm{g}$ seed and leaf extracts, respectively, whereas about $60 \%$ scavenging was found with $300 \mu \mathrm{g}$ husk extract. The leaf extract $(300 \mu \mathrm{g})$ showed the maximum (80\%) superoxide scavenging activity, whereas about 40 and $30 \%$ scavenging activity was observed with seed and husk extracts $(300 \mu \mathrm{g})$, respectively (Figure 6C). Notably, the maximum reducing activity (20\%) was shown by the husk extract $(80 \mu \mathrm{g})$, followed by that of leaves and seeds extracts (Figure 6D).

\section{Metabolites Profiling}

Thirteen different metabolites were identified in leaf and seed extracts, whereas 10 metabolites were found in the husk (Table 3). In total, eight alkaloids and flavonoids were detected in the leaf extract followed by five in that of the seed and one in the husk extract. No alkaloids were present in the leaf extract, whereas an alkaloid pinidine $(\mathrm{m} / \mathrm{z} 122.13)$ was detected in the husk extract and, two alkaloids, lunamarine (punarnavine; $\mathrm{m} / \mathrm{z} 104.04)$ and hordatine $B(\mathrm{~m} / \mathrm{z} 545.3)$, were observed in the seed extract. A total of seven nutraceutical flavonoids; luteolin ( $\mathrm{m} / \mathrm{z}$ 815.17), quercetagetin (m/z 815.17), kaempferol ( $\mathrm{m} / \mathrm{z}$ 815.17), syringetin ( $\mathrm{m} / \mathrm{z}$ 815.17), limocitrin $(\mathrm{m} / \mathrm{z}$ 815.17), catechin/epicatechin/pavetannin B2 (m/z 847.19) and helilupolone (m/z 155.1) were detected exclusively in leaf extract. Similarly, two flavonoids; prorepensin (m/z 527.31) and morusin/kuwanon $\mathrm{B} /$ cyclomulberrin $(\mathrm{m} / \mathrm{z}$ 141.06) were only identified in the seed extract, whereas the flavonoid dorsmanin $\mathrm{F}(\mathrm{m} / \mathrm{z}$ 221.1) was detected in both leaf and seed extracts. Flavonoids were not detected in husk extracts. Anthocyanidins and carotenoids, including cyanidin ( $\mathrm{m} / \mathrm{z} 816.19)$, malvidin $(\mathrm{m} / \mathrm{z}$ $817.23)$ and rhodopin/OH-lycopene ( $\mathrm{m} / \mathrm{z} 555.45)$, were only identified in the leaf extract. No terpenes were detected in the leaf extract, whereas six and four different terpenes were found in the seed and husk extracts, respectively. Out of six terpenes, five were exclusively detected in seed extract; cinncassiol C (m/z 381.19), ampeloside Bf2 (m/z 985.51), prosapogenin 


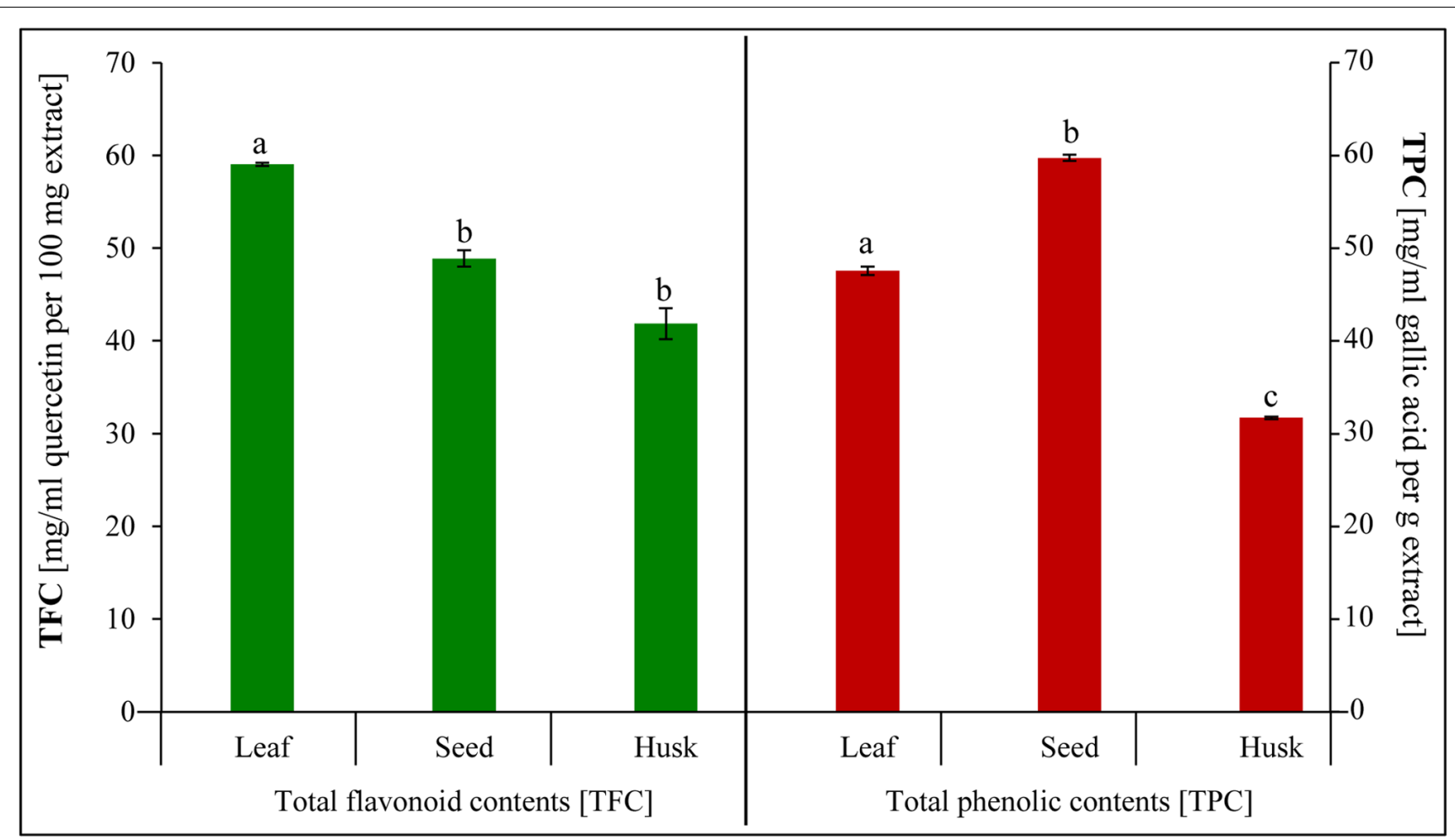

FIGURE 5 | Total phenolic and total flavonoid contents extracted from psyllium leaves, seeds, and husk. Value represents the mean \pm SE and values with different letters are significant different at $p<0.05$.

(m/z 663.37), spinasaponin A (m/z 795.44), and medicagenic acid $(\mathrm{m} / \mathrm{z} 413.2)$. The triterpene saponin, cynarasaponin $\mathrm{H}(\mathrm{m} / \mathrm{z}$ 891.48) was found in both seed and husk extracts. Similarly, three triterpenes; narasin B (m/z 382.25), ginsenoside $\mathrm{Rg} 6(\mathrm{~m} / \mathrm{z}$ $384.25)$ and periandrin I ( $\mathrm{m} / \mathrm{z} 855.44)$ were only identified in the husk extract. A natural phytoalexin, pterostilbene (m/z 221.1) was detected in both leaf and seed extracts, whereas a food-flavoring agent, 2-phenylethanethiol (m/z 139.06) and a phenylpropanoid, coriandrin $(\mathrm{m} / \mathrm{z}$ 231.07), were identified exclusively in the seed and leaf extracts, respectively. Similarly, metabolites with diverse nutraceutical characteristics, including sarmentine $(\mathrm{m} / \mathrm{z}$ 204.18), purmorphamine (m/z 261.14), tapentadol (m/z 204.18), zolmitriptan ( $\mathrm{m} / \mathrm{z} 270.16)$, and withaperuvin $(\mathrm{m} / \mathrm{z} 261.14)$ were only identified in the husk extract.

\section{Flavonoid Biosynthesis Pathway Analysis}

Using metabolomic data (Supplementary Table S2), a flavonoid biosynthesis pathway was mapped (Figure 7) by in silico comparative homology analysis. For this pathway enrichment analysis was performed with the pathway topology using the KEGG metabolic pathways database of Oryza sativa japonica and Arabidopsis thaliana. The impact of comparative pathway topology analysis showed a maximum interactive degree of centrality with flavonoid biosynthesis (Supplementary Table S4). A graphical output contained three levels of view; metabolome view, pathway view and compound view (Figure 8). A probable flavonoid biosynthesis pathway was deduced using the interactive metabolome pathway view that was generated dynamically on the MetaboAnalyst system (Figure 7).

\section{DISCUSSION}

Plantago species are considered to be a natural reservoir of diverse biologically active secondary metabolites, such as lipids, flavonoids, alkaloids, and terpenoids (Samuelsen, 2000). Psyllium husk (isabgol) is used worldwide as a dietary fiber supplement to relieve constipation, irritable bowel syndrome and diarrhea. Furthermore, it has also been recognized as a cholesterollowering agent for use in hypercholesterolemia (Anderson et al., 1990). In recent years, natural antioxidants from different plant sources have gained increasing attention (Mishra et al., 2015) and $P$. ovata plant tissues are rich in bioactive compounds, including different types of metabolites, such as polyphenols and flavonoids (Talukder et al., 2015), which are well-known natural antioxidants.

Essential FAs, including alpha-linolenic acid (a $\omega-3$ fatty acid) and linoleic acid (a $\omega-6$ fatty acid) cannot be synthesized de novo in sufficient quantity in humans and is therefore outsourced by the human body from food (Food and Agriculture Organization, 2010). A bi-plot data matrix of the total lipids and fatty acids successfully explained $100 \%$ of the variance (PC1 - 55.27\% and PC2 - 44.73\%) and revealed correlations between FAs and plant parts (Figure 2). Overall, the PCA exhibited a statistical 

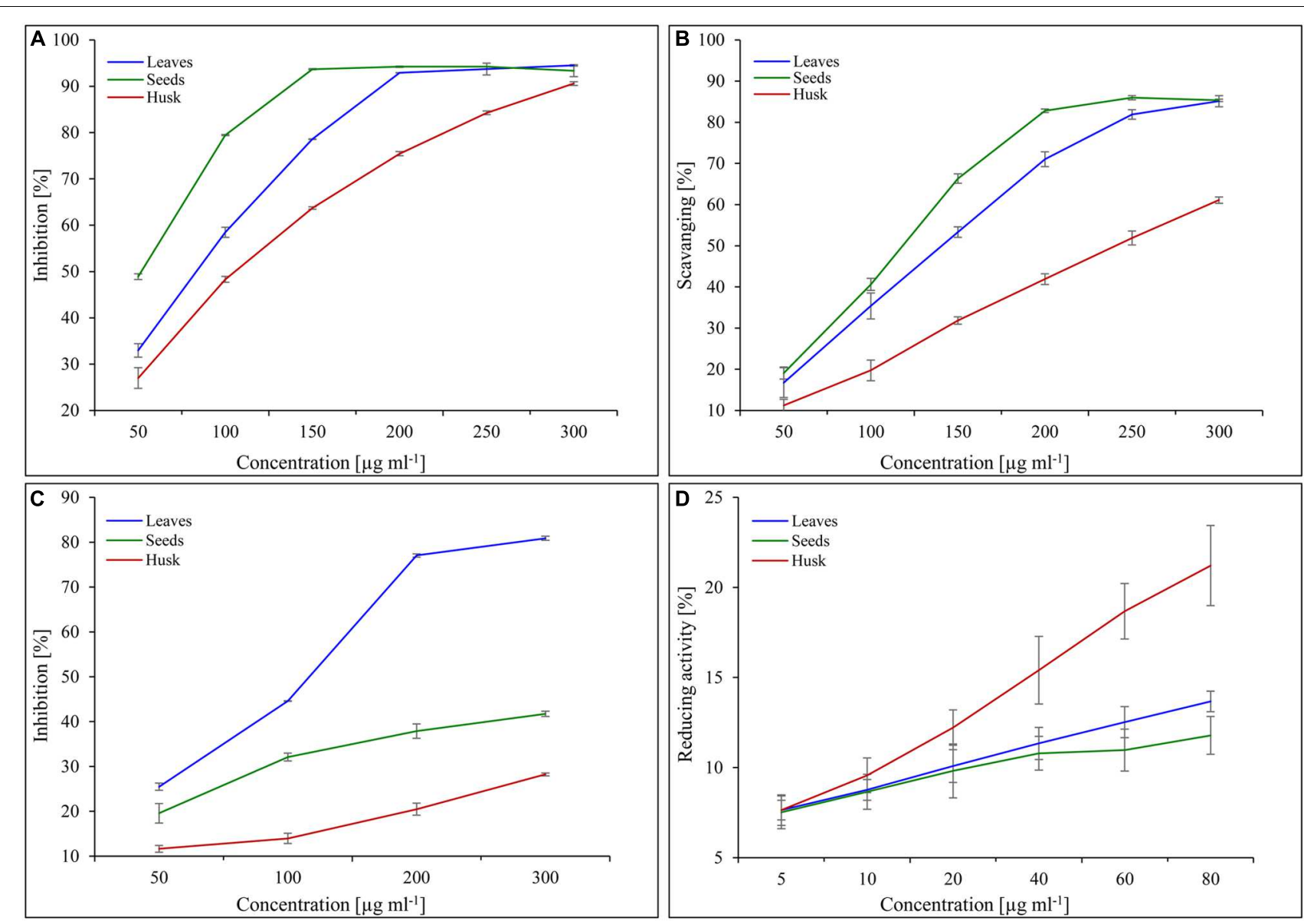

FIGURE 6 | Scavenging and reducing activities of psyllium extracts obtained from different plant parts. Total antioxidant (A), DPPH scavenging (B), superoxide free radicals scavenging (C) and reducing activities (D) of psyllium leaves, seeds, and husk extracts. Value represents the mean \pm SE.

distinction among the total lipids and fatty acids composition of different plant parts. In the present study, different psyllium plant parts, such as leaves, seeds and the husk were found to be a rich source of essential $\omega-3$ and $\omega-6$ fatty acids that are involved in human physiology (Table 1). About 14.57, 17.39, and $0.76 \mathrm{mg} \mathrm{g}^{-1}$ alpha-linolenic acid (ALA, $\omega-3 \mathrm{FA}$ ) were detected in leaves, seeds and the husk respectively (Supplementary Table S3). Seed oils are considered rich source of ALA, which is one of the essential fatty acid and cannot be produced within the human body. Additionally, psyllium was found to be a rich source of PUFAs, which are imperative nutritional indicators that demonstrate the nutraceutical importance of the plant (Gill and Valivety, 1997a). Furthermore, PUFAs have a number of non-edible biotechnological applications, including drying oils and biotransformations (Gill and Valivety, 1997b). In addition to fatty acids, a higher content of the essential amino acid valine was found in psyllium leaves followed by sulfur-rich amino acids (Figure 4), compared to the FAO recommended reference pattern (Food and Agriculture Organization, 2013). The essential amino acid leucine and the sulfur-rich amino acids cysteine and methionine were not detected in the husk. This implies that psyllium leaves are a rich source of essential amino acid (valine) and fatty acids ( $\omega-3$ fatty acid, alpha-linolenic acid and $\omega-6$ fatty acid, linoleic acid) and can therefore act as a dietary supplement. Ideal daily fat intake is $55-83 \mathrm{~g}$, which is $20-30 \%$ (500-700 calories) of daily energy requirement, i.e., 2500 calories (Food and Board, 1989). Results demonstrated that $100 \mathrm{~g}$ psyllium leaves contain $2.62 \mathrm{~g}$ fat, in result about 24 calories energy. There are 0.24 and $0.15 \mathrm{~g}$ fat in $100 \mathrm{~g}$ of mixed salad greens and Lettuce green leaves salad, which give 2.2 and 1.4 calories in the term of fat, respectively. In total (including fat, carbohydrate and proteins), there is 17 calories in $100 \mathrm{~g}$ of mixed salad greens, whereas 15 calories in $100 \mathrm{~g}$ of Lettuce green leaves salad (USDA, 2014). The recommended daily intake of essential amino acids, histidine, isoleucine, leucine, lysine, threonine, and valine are 10 , $20,39,30,15,26 \mathrm{mg} / \mathrm{kg}$-weight/day, respectively for adults (Food and Board, 1989). Psyllium leaves contain 0.28, 1.17, 0.93, 0.27, 0.95 , and $2.79 \mathrm{~g}$ histidine, isoleucine, leucine, lysine, threonine, and valine per $100 \mathrm{~g}$ of biomass, respectively. About $100 \mathrm{~g}$ leaves provide 56,48 , and $18 \%$ daily requirement of histidine, leucine, and lysine to an adult of an average weight $50 \mathrm{~kg}$. Furthermore, $100 \mathrm{~g}$ leaves fulfill more than recommended daily requirement of isoleucine (117\%), threonine (127\%), and valine (215\%). Taken together, daily fat intake and essential amino acids, psyllium 
TABLE 3 | Probable metabolites and their possible application/role identified in different plant part of psyllium.

\begin{tabular}{|c|c|c|c|c|}
\hline Probable metabolites & Leaves & Seeds & Husk & Possible properties/function/applications \\
\hline \multicolumn{5}{|l|}{ Alkaloids and flavonoids } \\
\hline Lunamarine (punarnavine) & nd & $\sqrt{ }$ & nd & Alkaloid (quinolone): anticancer, antiestrogenic, immunomodulatory, and anti-amoebic \\
\hline Hordatine B & nd & $\sqrt{ }$ & nd & Alkaloid: phytoalexin \\
\hline Pinidine & nd & nd & $\sqrt{ }$ & Alkaloid \\
\hline Luteolin & $\sqrt{ }$ & nd & nd & Flavonoid: flavone, nutriceutical, and anticancer \\
\hline Quercetagetin & $\sqrt{ }$ & nd & nd & Flavonoid: flavonol \\
\hline Kaempferol & $\sqrt{ }$ & nd & nd & Flavonoid: flavonol \\
\hline Syringetin & $\sqrt{ }$ & nd & nd & Flavonoid: flavonol \\
\hline Limocitrin & $\sqrt{ }$ & nd & nd & Flavonoid: flavonol \\
\hline Catechin/epicatechin/pavetannin B2 & $\sqrt{ }$ & nd & nd & Flavonoid: flavonol \\
\hline Helilupolone & $\sqrt{ }$ & nd & nd & Flavonoid \\
\hline Dorsmanin F & $\sqrt{ }$ & $\sqrt{ }$ & nd & Flavonoid: flavanone, antineoplastic activity \\
\hline Prorepensin & nd & $\sqrt{ }$ & nd & Flavonoid \\
\hline Morusin/kuwanon B/cyclomulberrin & nd & $\sqrt{ }$ & nd & Flavonoid: flavone, anti-tumor, and anti-nociceptive activity \\
\hline \multicolumn{5}{|l|}{ Anthocyanidins and carotenoids } \\
\hline Cyanidin & $\sqrt{ }$ & nd & nd & Anthocyanidin: antioxidant \\
\hline Malvidin & $\sqrt{ }$ & nd & nd & Anthocyanidin: antioxidant and anticancer (chemopreventive) \\
\hline Rhodopin/OH-lycopene & $\sqrt{ }$ & nd & nd & Carotenoid: antioxidant and singlet oxygen quencher \\
\hline \multicolumn{5}{|l|}{ Terpenes } \\
\hline Cinncassiol C & nd & $\sqrt{ }$ & nd & Diterpene: sesquiterpenoid \\
\hline Narasin B & nd & nd & $\sqrt{ }$ & Diterpene glycoside: antibiotic \\
\hline Ginsenoside Rg6 & nd & nd & $\sqrt{ }$ & Triterpene glycoside \\
\hline Ampeloside Bf2 & nd & $\sqrt{ }$ & nd & Triterpene glycoside: steroidal saponin \\
\hline Periandrin I & nd & nd & $\sqrt{ }$ & Triterpene glycoside; natural sweetener \\
\hline Prosapogenin & nd & $\sqrt{ }$ & nd & Triterpene saponin \\
\hline Spinasaponin A & nd & $\sqrt{ }$ & nd & Triterpene saponin \\
\hline Cynarasaponin $\mathrm{H}$ & nd & $\sqrt{ }$ & $\sqrt{ }$ & Triterpene saponin \\
\hline Medicagenic acid & nd & $\sqrt{ }$ & nd & Triterpenoid: oleanane triterpenoid \\
\hline \multicolumn{5}{|l|}{ Others } \\
\hline Pterostilbene & $\sqrt{ }$ & $\sqrt{ }$ & nd & Natural phenol: a phytoalexin \\
\hline 2-Phenylethanethiol & nd & $\sqrt{ }$ & nd & Aromatic homomonocyclic compound: a food flavoring agent \\
\hline Coriandrin & $\sqrt{ }$ & nd & nd & Phenylpropanoids and polyketides: exhibits anti-viral function \\
\hline Sarmentine & nd & nd & $\sqrt{ }$ & A natural herbicide \\
\hline Purmorphamine & nd & nd & $\sqrt{ }$ & $\begin{array}{l}\text { A therapeutic agent: activates the Hedgehog }(\mathrm{Hh}) \text { signaling pathway; induce osteoblast } \\
\text { differentiation, cardiomyocytes and neuronal differentiation }\end{array}$ \\
\hline Tapentadol & nd & nd & $\sqrt{ }$ & A therapeutic agent: analgesic \\
\hline Zolmitriptan & nd & nd & $\sqrt{ }$ & A therapeutic agent: used for the acute treatment of migraines \\
\hline Withaperuvin D/withaperuvin B & nd & nd & $\sqrt{ }$ & Withanolide \\
\hline
\end{tabular}

nd, not detected; $\sqrt{ }$ : present (detected).

leaves can be used as a green salad together with daily food as a dietary supplement.

Phytochemicals (secondary metabolites), including flavonoids, phenolic acids and polyphenols, are potent antioxidants are ubiquitous in plants and are an essential part of the human diet (Embuscado, 2015; Mishra et al., 2015). Psyllium seeds contained a higher total phenolic content than leaves and the husk (Figure 5), and therefore show a higher total antioxidant and DPPH scavenging activity, followed by leaves and the husk (Figures 6A,B). The maximum total flavonoid content was detected in leaves followed by seeds and the husk (Figure 5); leaves also possess high superoxide scavenging activity, whereas the husk showed the maximum reducing activity (Figures 6C,D). Thus, a positive correlation was observed between the phenolic and flavonoid contents, and the antioxidant and scavenging activities of psyllium plant parts. Secondary metabolites are considered to be efficient antioxidants and important radical scavengers, and also possess biological activities (Shahidi and Ambigaipalan, 2015). Antioxidant activities inhibit oxidation processes of functional food ingredients and thus, play a key role in promoting health (Shahidi and Ambigaipalan, 2015). Scavenging and antioxidant activities depend on the content of polyphenolics and flavonoids (Shahidi and Ambigaipalan, 2015). Similar to the finding in this study, a direct correlation was observed between scavenging and antioxidant activities, and the content of polyphenolics and flavonoids in Cumin, Salicornia, and Plantago (Mishra et al., 2015; Pandey et al., 2015; Talukder et al., 2015). The total antioxidant and DPPH scavenging activity 


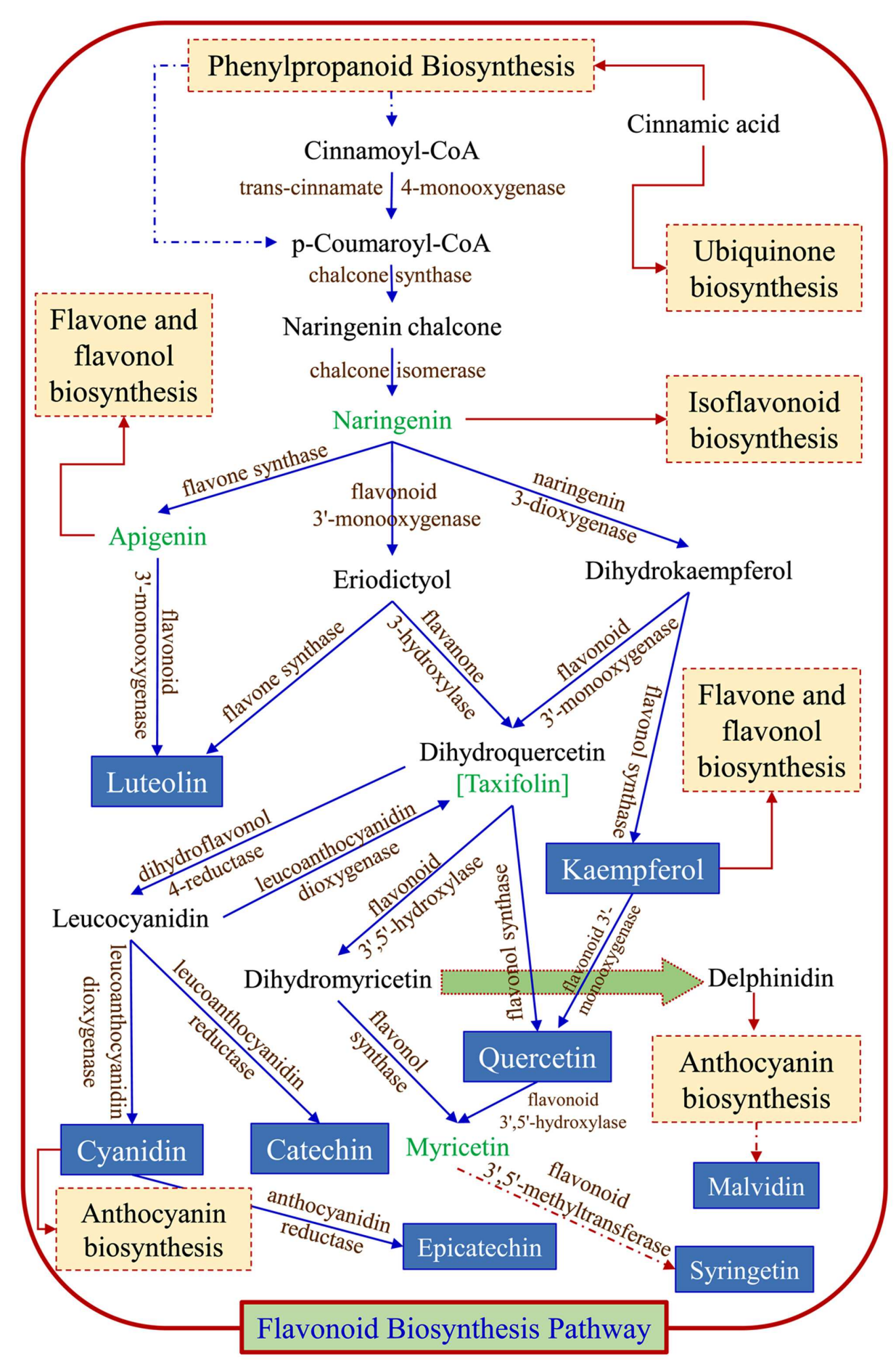

FIGURE 7 | Probable flavonoid biosynthesis pathway inferred in psyllium. Blue arrows $(\longrightarrow)$ are part of flavonoid biosynthesis pathway; dark red arrows indicate that compound enters in another pathways $(\longrightarrow)$, and dotted line/arrows indicate the presence of intermediates.

increased concomitantly with the polyphenolic and flavonoid content during different stages of in vitro callus culture of P. ovata (Talukder et al., 2015). Similarly, a correlation factor in terms of reciprocal values was established between the total phenolic and flavonoid content, and the antioxidant activity of shoot extracts of some selected Plantago species (Beara et al., 2009).

Previous studies have revealed that Plantago species are an excellent source of secondary metabolites with widespread applications in the nutraceutical industry (Samuelsen, 2000; 


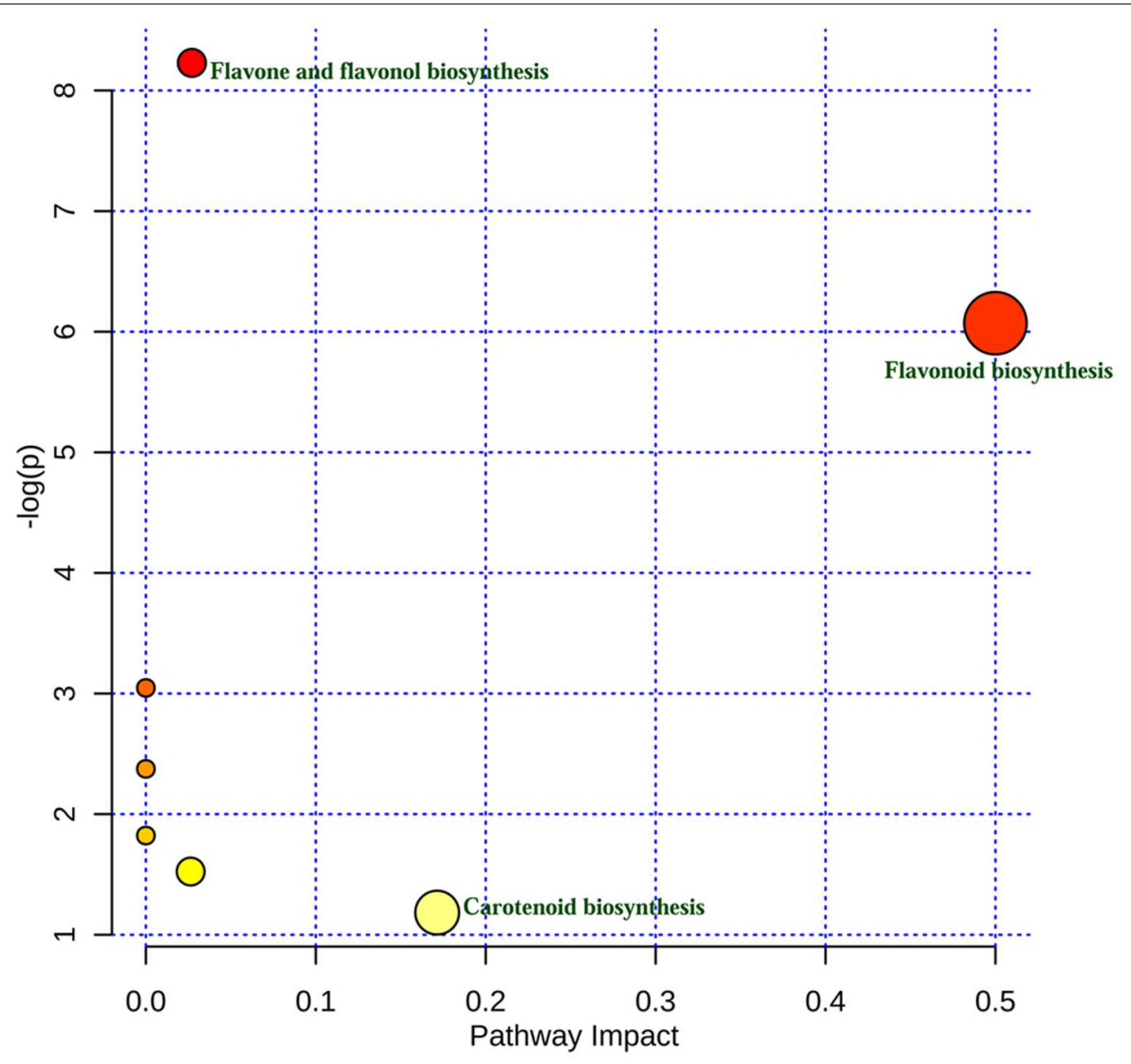

FIGURE 8 | Interactive graphical output of metabolic pathway analysis.

Beara et al., 2009), and in the present study, about 13 different metabolites were identified in leaf and seed extract of psyllium, whereas 10 metabolites were found in the husk (Table 3). This study is the first report on the untargeted metabolomics of different psyllium ( $P$. ovata) plant parts (leaves, seeds, and husk). Most flavonoids were detected in psyllium leaf extract, whereas terpenes were abundant in the seed extract. Flavonoids perform distinctive functions in plant metabolic pathways, including pigmentation, nutrition and defense (Horborne and Williams, 2000). Metabolites, apigenin, luteolin, rutin, quercetin, scutellarein, flavonoids, and triterpene acids were reported from leaves of Plantago species, especially from $P$. major, for a range of biological activities, including wound healing, antiinflammatory, analgesic, antioxidant, weak antibiotic, immunemodulating and antiulcerogenic activity (Kawashty et al., 1994; Samuelsen, 2000; Beara et al., 2009; Gonçalves and Romano, 2016). Furthermore, plant leaves were also used to cure asthma, bronchitis, pulmonary diseases, and diabetes (Samuelsen, 2000; Gonçalves and Romano, 2016).

Most metabolites, including lunamarine, luteolin, quercetagetin, kaempferol, syringetin, catechin, epicatechin, helilupolone, cyanidin, malvidin and quercetin are phenolics, flavonoids or alkaloids and contain potent antioxidant activities
(Grotewold, 2006; Gould and Lister, 2006; Mishra et al., 2015). These metabolites are known to be natural antioxidants and nutrient supplements, and provide functional value for the plant by modulating cell-signaling pathways (Williams et al., 2004). Plant flavonoids are divided into six major groups; chalcones, flavones, flavonols, flavandiols, anthocyanins, and condensed tannins (or proanthocyanidins); whereas a seventh group, aurones, is also present, but is not ubiquitous (Winkel-Shirley, 2001). Moreover, isoflavonoids are commonly synthesized by legumes. The alkaloid, lunamarine or punarnavine was detected exclusively in psyllium seed extract and displays a number of pharmaceutical applications, including anti-cancer, anti-estrogenic, immunomodulatory and anti-amoebic activities (Manu and Kuttan, 2009; Sreeja and Sreeja, 2009). Another alkaloid, hordatine B, which is ubiquitous in barley (Smith and Best, 1978), was also detected only in the seed extract, and is a well-known phytoalexin that confers antifungal activity to germinating seeds (Stoessl and Unwin, 1970). The flavonoids morusin and prorepensin were detected exclusively in seed extracts and are reported to be a potent antitumor agent and antioxidant, respectively (Tseng et al., 2010). The flavonoid, dorsmanin $\mathrm{F}$ was found in leaf and seed extracts, and is known for its anti-neoplastic activity (Kuete et al., 2015). 
The flavonoids luteolin and quercetin, which were only detected in psyllium leaf extracts, show potential for cancer prevention and therapy (Lin et al., 2008; Zhang et al., 2014). A potent antioxidant, kaempferol, known for a wide range of pharmacological activities, is used for numerous preclinical studies, due to its antioxidant, anti-inflammatory, anti-microbial, anti-cancer, cardioprotective, neuroprotective, antidiabetic, anti-osteoporotic, estrogenic/antiestrogenic, anxiolytic, analgesic and antiallergic activities (CalderonMontano et al., 2011). The flavonoid syringetin is reported to stimulate osteoblast differentiation (Hsu et al., 2009), whereas other flavonoids, including limocitrin, catechin/epicatechin, pavetannin, helilupolone, kuwanon B, and cyclomulberrin contain antioxidant activities. Anthocyanidins, including cyanidin, malvidin, and rhodopin/OH-lycopene were detected exclusively in psyllium leaf extracts and are natural antioxidants. Antioxidant metabolites (flavonoids and anthocyanidins) were predominant in psyllium leaf extracts and therefore, plant leaves can be further explored in terms of their antioxidants. Psyllium seed and husk extracts contained terpenes, including saponins (Table 3), and previous studies demonstrated that saponins might possess anticancer activity (Gurfinkel and Rao, 2003; Zhu et al., 2005). Psyllium seed extract was observed to be a potent source of saponins (terpenes) and saponins are thought to contribute natural plant defenses against pathogens and to act as scavengers of ROS; additionally, they have wide applications in the food, cosmetic and pharmaceutical industries (Güçlü-Üstündağ and Mazza, 2007).

In plants, the flavonoid biosynthesis pathway has gained importance throughout the world and it is one of the most intensively studied pathways (Grotewold, 2006). Flavonoid biosynthesis was developmentally or environmentally controlled by transcriptional regulatory networks; MYB-bHLH-WDR complexes, which are well-conserved in higher plants (Xu et al., 2015). In this study, the existence of a potential flavonoid biosynthesis pathway was inferred (Figure 7) using metabolomic data and a pathway topology module by in silico comparative homology analysis. The pathway includes a probable route for the biosynthesis of metabolites that were detected in different plant parts (Table 3). Furthermore, the nexus of different pathways such as the flavone and flavonol, isoflavonoid, anthocyanin and ubiquinone biosynthesis pathways was also observed. The flavonoid biosynthesis was started with general phenylpropanoid metabolism and leading to the major subgroup pathways; flavones and flavonol, isoflavonoid, and anthocyanin biosynthesis pathways. Metabolites, apigenin and kempferol lead to flavones and flavonol pathway, whereas cyanidin and delphinidin enter into anthocyanin biosynthesis pathway. Metabolite naringenin intermediates between flavonoid and isoflavonoid biosynthesis

\section{REFERENCES}

Ahmad, M. S., Ahmad, M. U., and Osman, S. M. (1980). A new hydroxyolefinic acid from Plantago major seed oil. Phytochemistry 19, 2137-2139. doi: 10.1016/S0031-9422(00)82210-4 pathway. The major metabolites end products are luteolin, catechin, epicatechin, syringetin, kempferol, cyanidin, and quercetin, which were also detected by LC MS analysis. The proposed illustration provides a paradigm to understand the transcriptional regulation of flavonoid biosynthesis and to engineer metabolic pathways accordingly to the demands of the nutraceutical industry.

\section{CONCLUSION}

This study reveals that psyllium ( $P$. ovata Forsk) contains nutritional antioxidants, flavonoids, PUFAs, including essential fatty acids ( $\omega-3$ and $\omega-6$ fatty acids), sulfur-rich and essential amino acids, and metabolites with bioactivities, which make it a promising candidate for use in the nutraceutical industry. Additionally, psyllium leaves can be used as a green salad together with daily food as a dietary supplement. As a future perspective, the flavonoid biosynthesis pathway illustrated here provides useful insight and opens a new avenue to select regulatory gene(s) for metabolic engineering.

\section{AUTHOR CONTRIBUTIONS}

Conceived and designed the experiments: AM and BJ. Performed the experiments: MP. Analyzed the data: MP and AM. Wrote the paper: MP and AM.

\section{FUNDING}

The authors acknowledge financial support from the Council of Scientific and Industrial Research (CSIR) and the Government of India, New Delhi [BSC0106-BioprosPR].

\section{ACKNOWLEDGMENT}

The authors would like to acknowledge CSIR-CSMCRI Communication No. PRIS- 168/2015. Analytical Discipline and the Centralized Instrument Facility of the institute are duly acknowledged for helping in running samples for the analytical analysis.

\section{SUPPLEMENTARY MATERIAL}

The Supplementary Material for this article can be found online at: http://journal.frontiersin.org/article/10.3389/fpls.2016.00431

Aittokallio, T., and Schwikowski, B. (2006). Graph-based methods for analysing networks in cell biology. Brief. Bioinform. 7, 243-255. doi: 10.1093/bib/bbl022

Al-Fayez, M., Cai, H., Tunstall, R., Steward, W. P., and Gescher, A. J. (2006). Differential modulation of cyclooxygenase-mediated prostaglandin production by the putative cancer chemopreventive flavonoids tricin, apigenin and 
quercetin. Cancer Chemoth. Pharm. 58, 816-825. doi: 10.1007/s00280-0060228-3

Anderson, J. W., Deakins, D. A., Floore, T. L., Smith, B. M., and Whitis, S. E. (1990). Dietary fiber and coronary heart disease. Crit. Rev. Food Sci. Nut. 29, 95-147. doi: $10.1080 / 10408399009527518$

Balasundram, N., Sundram, K., and Samman, S. (2006). Phenolic compounds in plants and agri-industrial by-products: antioxidant activity, occurrence, and potential uses. Food Chem. 99, 191-203. doi: 10.1016/j.foodchem.2005.07.042

Beara, I. N., Lesjak, M. M., Jovin, E. Đ, Balog, K. J., Anačkov, G. T., Orčicì, D. Z., et al. (2009). Plantain (Plantago L.) species as novel sources of flavonoid antioxidants. J. Agri. Food Chem. 57, 9268-9273. doi: 10.1021/jf902205m

Bligh, E. G., and Dyer, W. J. (1959). A rapid method of total lipid extraction and purification. Can. J. Biochem. Phys. 37, 911-917. doi: 10.1139/o59-099

Braca, A., Sortino, C., Politi, M., Morelli, I., and Mendez, J. (2002). Antioxidant activity of flavonoids from Licania licaniaeflora. J. Ethnopharmacol. 79, 379381. doi: 10.1016/S0378-8741(01)00413-5

Calderon-Montano, J. M., Burgos-Morón, E., Pérez-Guerrero, C., and LópezLázaro, M. (2011). A review on the dietary flavonoid kaempferol. Mini Rev. Med. Chem. 11, 298-344. doi: 10.2174/138955711795305335

Chaturvedi, A. K., Patel, M. K., Mishra, A., Tiwari, V., and Jha, B. (2014). The SbMT-2 gene from a halophyte confers abiotic stress tolerance and modulates ROS scavenging in transgenic tobacco. PLOS ONE 9:e111379. doi: 10.1371/journal.pone.0111379

Chevallier, A. (1996). The Encyclopedia of Medicinal Plants. (London: Dorling Kindersley), 336.

Dersch, L. M., Beckers, V., and Wittmann, C. (2016). Green pathways: metabolic network analysis of plant systems. Metab. Eng. 34, 1-24. doi: 10.1016/j.ymben.2015.12.001

Embuscado, M. E. (2015). Spices and herbs: natural sources of antioxidants-a mini review. J. Funct. Foods 18, 811-819. doi: 10.1016/j.jff.2015.03.005

Fiehn, O. (2002). Metabolomics-the link between genotypes and phenotypes. Plant Mol. Biol. 48, 155-171. doi: 10.1023/A:1013713905833

Fillet, M., and Frédérich, M. (2015). The emergence of metabolomics as a key discipline in the drug discovery process. Drug Discov. Today Technol. 13, 19-24. doi: 10.1016/j.ddtec.2015.01.006

Food and Agriculture Organization (2010). Fats and Fatty Acids in Human Nutrition. Report of an FAO Expert Consultation. Rome: Food and Agriculture Organization of the United Nations.

Food and Agriculture Organization (2013). Dietary Protein Quality Evaluation in Human Nutrition. Report of an FAO Expert Consultation. Rome: Food and Agriculture Organization of the United Nations.

Food, U. S., and Board, N. (1989). Recommended Dietary Allowances. National Research Council Report and Circular Series, 115. Washington, DC: National Academy of Sciences, United State Food and Nutrition Board.

Gill, I., and Valivety, R. (1997a). Polyunsaturated fatty acids, part 1: occurrence, biological activities and applications. Trends Botechnol. 15, 401-409. doi: 10.1016/S0167-7799(97)01076-7

Gill, I., and Valivety, R. (1997b). Polyunsaturated fatty acids, part 2: biotransformations and biotechnological applications. Trends Biotechnol. 15, 470-478. doi: 10.1016/S0167-7799(97)01077-9

Gonçalves, S., and Romano, A. (2016). The medicinal potential of plants from the genus Plantago (Plantaginaceae). Ind. Crops Prod. 83, 213-226. doi: 10.1016/j.indcrop.2015.12.038

Gould, K. S., and Lister, C. (2006). "Flavonoid functions plants," in Flavonoids: Chemistry, Biochemistry and Applications, eds $\varnothing$. M. Andersen and K. R. Markham (Boca Raton, FL: CRC Press), 397-441.

Grotewold, E. (ed.). (2006). The Science of Flavonoids. (New York: Springer), 36-37. Güçlü-Üstündağ, Ö., and Mazza, G. (2007). Saponins: properties, applications and processing. Cr. Rev. Food Sci. Nutr. 47, 231-258. doi: 10.1080/10408390600698197

Gurfinkel, D. M., and Rao, A. V. (2003). Soyasaponins: the relationship between chemical structure and colon anticarcinogenic activity. Nutr. Cancer 47, 24-33. doi: 10.1207/s15327914nc4701_3

Harborne, J. B. (1973). Phytochemical Methods. London: Chapman and Hall Ltd., 49-188.

Hazra, B., Biswas, S., and Mandal, N. (2008). Antioxidant and free radical scavenging activity of Spondias pinnata. BMC Complement. Altern. Med. 8:63. doi: $10.1186 / 1472-6882-8-63$
Horborne, J. B., and Williams, C. A. (2000). Advances in flavonoid research since 1992. Phytochemistry 55, 481-504. doi: 10.1016/S0031-9422(00)00235-1

Hsu, Y. L., Liang, H. L., Hung, C. H., and Kuo, P. L. (2009). Syringetin, a flavonoid derivative in grape and wine, induces human osteoblast differentiation through bone morphogenetic protein-2/extracellular signal-regulated kinase 1/2 pathway. Mol. Nutr. Food Res. 53, 1452-1461. doi: 10.1002/mnfr.200800483.

Jat, R. S., Reddy, R. N., Bansal, R., and Manivel, P. (2015). Good Agricultural Practices for Isabgol. Anand: ICAR - Directorate of Medicinal and Aromatic Plants Research.

Jorge, T. F., Rodrigues, J. A., Caldana, C., Schmidt, R., van Dongen, J. T., ThomasOates, J., et al. (2015). Mass spectrometry-based plant metabolomics: metabolite responses to abiotic stress. Mass Spectrom. Rev. doi: 10.1002/mas.21449 [Epub ahead of print].

Joshi, M., Jha, A., Mishra, A., and Jha, B. (2013). Developing transgenic Jatropha using the SbNHX1 gene from an extreme halophyte for cultivation in saline wasteland. PLoS ONE 8:e71136. doi: 10.1371/journal.pone.0071136

Kawashty, S. A., Abdalla, M. F., and Saleh, N. A. M. (1994). Flavonoids of Plantago species in Egypt. Biochem. Syst. Ecol. 22, 729-733. doi: 10.1016/03051978(94)90058-2

Khakimov, B., Bak, S., and Engelsen, S. B. (2014). High-throughput cereal metabolomics: current analytical technologies, challenges and perspectives. J. Cereal Sci. 59, 393-418. doi: 10.1016/j.jcs.2013.10.002

Khan, S. B., Kong, C., Kim, J., and Kim, S. (2010). Protective effect of Amphiroa dilatata on ROS induced oxidative damage and MMP expressions in HT1080 cells. Biotechnol. Bioproc. Eng. 15, 191-198. doi: 10.1007/s12257-009-0052-9

Kirtikar, K. R., and Basu, B. D. (1918). "Indian medicinal plants," in 1935 and International Book Distributors, ed. L. M. Basu (Mumbai: Panini Office).

Kuete, V., Mbaveng, A. T., Zeino, M., Ngameni, B., Kapche, G. D. W., Kouam, S. F., et al. (2015). Cytotoxicity of two naturally occurring flavonoids (dorsmanin $\mathrm{F}$ and poinsettifolin B) towards multi-factorial drug-resistant cancer cells. Phytomedicine 22, 737-743. doi: 10.1016/j.phymed.2015.04.007

Kumari, P., Bijo, A. J., Mantri, V. A., Reddy, C. R. K., and Jha, B. (2013). Fatty acid profiling of tropical marine macroalgae: an analysis from chemotaxonomic and nutritional perspectives. Phytochemistry 86, 44-56. doi: 10.1016/j.phytochem.2012.10.015

Kwanyuen, P., and Burton, J. W. (2010). A modified amino acid analysis using PITC derivatization for soybeans with accurate determination of cysteine and half-cystine. J. Am. Oil Chem. Soc. 87, 127-132. doi: 10.1007/s11746-009-1484-2

Lin, Y., Shi, R., Wang, X., and Shen, H. M. (2008). Luteolin, a flavonoid with potentials for cancer prevention and therapy. Curr. Cancer Drug Tar. 8, 634646. doi: 10.2174/156800908786241050

Manu, K. A., and Kuttan, G. (2009). Immunomodulatory activities of Punarnavine, an alkaloid from Boerhaavia diffusa. Immunopharm. Immunot. 31, 377-387. doi: 10.1080/08923970802702036

Mishra, A., and Jha, B. (2009). Isolation and characterization of extracellular polymeric substances from micro-algae Dunaliella salina under salt stress. Bioresour. Technol. 100, 3382-3386. doi: 10.1016/j.biortech.2009.02.006

Mishra, A., Patel, M. K., and Jha, B. (2015). Non-targeted metabolomics and scavenging activity of reactive oxygen species reveal the potential of Salicornia brachiata as a functional food. J. Funct. Foods 13, 21-31. doi: 10.1016/j.jff.2014.12.027

Niki, E., Shimaski, H., and Mino, M. (1994). Antioxidantism-Free Radical and Biological Defense. Tokyo: Gakkai Syuppn Center, 3-16.

Pandey, S., Patel, M. K., Mishra, A., and Jha, B. (2015). Physio-biochemical composition and untargeted metabolomics of cumin (Cuminum cyminum L.) make it promising functional food and help in mitigating salinity stress. PLoS ONE 10:e0144469. doi: 10.1371/journal.pone.0144469

Patel, M. K., Joshi, M., Mishra, A., and Jha, B. (2015). Ectopic expression of SbNHX1 gene in transgenic castor (Ricinus communis L.) enhances salt stress by modulating physiological process. Plant Cell Tiss. Org. 122, 477-490. doi: 10.1007/s11240-015-0785-4

Pichersky, E., and Gang, D. R. (2000). Genetics and biochemistry of secondary metabolites in plant an evolutionary perspective. Trends Plant Sci. 5, 439-445. doi: 10.1016/S1360-1385(00)01741-6

Poerschmann, J., Spijkerman, E., and Langer, U. (2004). Fatty acid patterns in Chlamydomonas sp. as a marker for nutritional regimes and temperature under extremely acidic conditions. Microb. Ecol. 48, 78-89. doi: 10.1007/s00248-0030144-6 
Re, R., Pellegrini, N., Proteggente, A., Pannala, A., Yang, M., and RiceEvans, C. (1999). Antioxidant activity applying an improved ABTS radical cation decolorization assay. Free Radical Biol. Med. 26, 1231-1237. doi: 10.1016/S0891-5849(98)00315-3

Rischer, H., Oresic, M., Seppanen-Laakso, T., Katajamaa, M., and Lammertyn, F. (2006). Gene-to-metabolite networks for terpenoid indole alkaloid biosynthesis in Catharanthus roseus cells. Proc. Natl. Acad. Sci. U.S.A. 103, 5614-5619. doi: 10.1073/pnas.0601027103

Saeed, N., Khan, M. R., and Shabbir, M. (2012). Antioxidant activity, total phenolic and total flavonoid contents of whole plant extracts Torilis leptophylla L. BMC Complement. Altern. Med. 12:221. doi: 10.1186/1472-6882-12-221

Samuelsen, A. B. (2000). The traditional uses, chemical constituents and biological activities of Plantago major L. A review. J. Ethnopharmacol. 71, 1-21. doi: 10.1016/S0378-8741(00)00212-9

Shahidi, F., and Ambigaipalan, P. (2015). Phenolics and polyphenolics in foods, beverages and spices: antioxidant activity and health effects-A review. J. Funct. Foods 18, 820-897. doi: 10.1016/j.jff.2015.06.018

Smith, T. A., and Best, G. R. (1978). Distribution of the hordatines in barley. Phytochemistry 17, 1093-1098. doi: 10.1016/S0031-9422(00)94295-X

Sofowora, A. (1993). Recent trends in research into African medicinal plants. J. Ethnopharmacol. 38, 197-208. doi: 10.1016/0378-8741(93)90017-Y

Sreeja, S., and Sreeja, S. (2009). An in vitro study on antiproliferative and antiestrogenic effects of Boerhaavia diffusa L. extracts. J. Ethnopharmacol. 126, 221-225. doi: 10.1016/j.jep.2009.08.041

Stoessl, A., and Unwin, C. H. (1970). The antifungal factors in barley. V. Antifungal activity of the hordatines. Can. J. Bot. 48, 465-470. doi: 10.1139/b70-066

Talukder, P., Talapatra, S., Ghoshal, N., and Raychaudhuri, S. S. (2015). Antioxidant activity and HPLC analysis of phenolic compounds during in vitro callus culture of Plantago ovata Forsk and effect of exogenous additives on accumulation of phenolic compounds. J. Sci. Food Agric. 96, 232-244. doi: 10.1002/jsfa.7086

Tiwari, V., Chaturvedi, A. K., Mishra, A., and Jha, B. (2015). Introgression of the SbASR-1 gene cloned from a halophyte Salicornia brachiata enhances salinity and drought endurance in transgenic groundnut (Arachis hypogaea) and acts as a transcription Factor. PLoS ONE 10:e0131567. doi: 10.1371/journal.pone.0131567

Töpfer, N., Kleessen, S., and Nikoloski, Z. (2015). Integration of metabolomics data into metabolic networks. Front. Plant Sci. 6:49. doi: 10.3389/fpls.2015.00049

Trease, G. E., and Evans, W. C. (1989). Pharmacognsy, 11th Edn. London: Brailliar Tiridel Can Macmillian Publishers, 60-75.

Tseng, T. H., Chuang, S. K., Hu, C. C., Chang, C. F., Huang, Y. C., Lin, C. W., et al. (2010). The synthesis of morusin as a potent antitumor agent. Tetrahedron 66, 1335-1340. doi: 10.1016/j.tet.2009.12.002

USDA (2014). USDA National Nutrient Database for Standard Reference, Release 28. Nutrient Data Laboratory, United State Department of Agriculture, Washington, DC.
Williams, R. J., Spencer, J. P., and Rice-Evans, C. (2004). Flavonoids: antioxidants or signalling molecules? Free Radical Biol. Med. 36, 838-849. doi: 10.1016/j.freeradbiomed.2004.01.001

Winkel-Shirley, B. (2001). Flavonoid biosynthesis. A colorful model for genetics, biochemistry, cell biology, and biotechnology. Plant Physiol. 126, 485-493. doi: 10.1104/pp.126.2.485

Xia, J., Sinelnikov, I. V., Han, B., and Wishart, D. S. (2015). MetaboAnalyst 3.0making metabolomics more meaningful. Nucleic Acids Res. 43, 251-257. doi: 10.1093/nar/gkv380

Xu, W., Dubos, C., and Lepiniec, L. (2015). Transcriptional control of flavonoid biosynthesis by MYB-bHLH-WDR complexes. Trends Plant Sci. 20, 176-185. doi: 10.1016/j.tplants.2014.12.001

Yu, X., Zhao, P., He, C., Li, J., Tang, X., Zhou, J., et al. (2012). Isolation of a novel strain of Monoraphidium minutum and characterization of its potential application as biodiesel feedstock. Bioresour. Technol. 121, 256-262. doi: 10.1016/j.biortech.2012.07.002

Zhang, W., Li, C., You, L. J., Fu, X., Chen, Y. S., and Luo, Y. Q. (2014). Structural identification of compounds from Toona sinensis leaves with antioxidant and anticancer activities. J. Funct. Foods 10, 427-435. doi: 10.1016/j.jff.2014. 07.015

Zhishen, J., Mengcheng, T., and Jianming, W. (1999). The determination of flavonoid content in mulberry and their scavenging effects on superoxide radicals. Food Chem. 64, 555-559. doi: 10.1016/S0308-8146(98)00102-2

Zhu, J., Xiong, L., Yu, B., and Wu, J. (2005). Apoptosis induced by a new member of saponin family is mediated through caspase-8-dependent cleavage of Bcl-2. Mol. Pharmacol. 68, 1831-1838. doi: 10.1124/mol.105.015826

Zhu, Z. J., Schultz, A. W., Wang, J., Johnson, C. H., Yannone, S. M., Patti, G. J., et al. (2013). Liquid chromatography quadrupole time-of-flight mass spectrometry characterization of metabolites guided by the METLIN database. Nat. Protoc. 8 , 451-460. doi: 10.1038/nprot.2013.004

Conflict of Interest Statement: The authors declare that the research was conducted in the absence of any commercial or financial relationships that could be construed as a potential conflict of interest.

The reviewer AG and handling Editor declared their shared affiliation, and the handling Editor states that the process nevertheless met the standards of a fair and objective review.

Copyright (c) 2016 Patel, Mishra and Jha. This is an open-access article distributed under the terms of the Creative Commons Attribution License (CC BY). The use, distribution or reproduction in other forums is permitted, provided the original author(s) or licensor are credited and that the original publication in this journal is cited, in accordance with accepted academic practice. No use, distribution or reproduction is permitted which does not comply with these terms. 